\title{
LOS CASINOS EN EL URUGUAY ${ }^{1}$
}

\section{CASINOS IN URUGUAY}

\section{CASINOS NO URUGUAI}

\author{
ISMAEL PIGNATTA SÁNCHEZ²
}

RESUMEN: En Uruguay existe un monopolio del Estado para la explotación de casinos, los cuales pueden ser desarrollados directamente por el Estado o a través de concesiones hacia los privados. Sin perjuicio de lo anterior también se desarrollan los operadores de máquinas tragamonedas clandestinas, los cuales lo realizan al margen del sistema legal, careciendo de todo tipo de autorización, control y auditorias, así como tampoco ofrecen ningún tipo de garantías a los consumidores.

Además, el desarrollo de los juegos de azar ha ido evolucionando de la forma tradicional desarrollada en casinos, a nuevas modalidades de juego como el juego on-line. Esto ha tomado muchísima fuerza en aquellos países que lo han regulado de forma acorde, abriendo un nuevo abanico de opciones para el desarrollo de este tipo de juegos de azar, siendo no solo una nueva realidad para los juegos de azar, sino el futuro de la industria.

Se ha planteado la discusión de si esta práctica monopólica del Estado es la apropiada, o si por el contrario se debe optar por una apertura de la misma, que sea manejada libremente por los privados y públicos, adecuando y aplicando los correspondientes mecanismos de control.

PALABRAS CLAVE: apuestas, juegos de azar, máquinas tragamonedas ilegales, juego online, casinos

ABSTRACT: In Uruguay, the casino industry is an activity that can only be developed directly by the State or through special authorizations (concessions) to private companies. Nevertheless, illegal slot machine operators are also found in the Uruguayan Gaming market: they move outside the legal system (monopoly of the activity by the State), lack all kinds of authorization, control and audits, and offer no type of guarantees to consumers.

The gaming industry has evolved from the traditional way developed in based casinos, to new gaming alternatives such as online gambling. This became very strong in

1 Tesina presentada el 4 de julio 2020 en el marco del Máster en Derecho (LLM) de la Universidad de Montevideo. Tutor: Dr. Camilo Martínez Blanco.

2 Doctor en Derecho y Ciencias Sociales por la Universidad de la República. ORCID ID: https: / /orcid.org/0000-00022141-9172 iPignatta@enjoy.cl 
those countries that have regulated online gaming accordingly, opening a new range of options for the development of this type of gaming, being not only a new reality for gambling, but the future of the industry.

Therefore, a discussion has been raised whether the way in which the Uruguayan gaming industry is developed (monopolistic practice) is appropriate, or if, on the contrary, it should be developed openly and freely by the private and public sector.

KEY WORDS: betting, gambling, illegal slot machines, online gambling, casinos

RESUMO: No Uruguai existe um monopólio estatal para a exploração de casinos, que pode ser desenvolvido directamente pelo Estado ou através de concessões a privados. Sem prejuízo do acima exposto, são também desenvolvidos operadores clandestinos de slot machines, que operam fora do sistema legal, sem qualquer tipo de autorização, controlo e auditorias, bem como sem oferecer garantias aos consumidores.

Além disso, o desenvolvimento de jogos de azar tem vindo a evoluir da forma tradicional desenvolvida nos casinos, para novas modalidades de jogo, tais como os jogos em linha. Isto tem tido muita força nos países que o regulamentaram em conformidade, abrindo uma nova gama de opções para o desenvolvimento deste tipo de jogos de azar, sendo não só uma nova realidade para o jogo, mas também o futuro da indústria.

Tem-se discutido se esta prática monopolista do Estado é apropriada, ou se pelo contrário deve ser aberta para ser livremente gerida pelos sectores privado e público, adaptando e aplicando os mecanismos de controlo correspondentes.

PALAVRAS - CHAVE: apostas, jogos de azar, slot machines ilegais, jogos de azar online, casinos

\section{IDENTIFICACIÓN DEL TEMA DE INVESTIGACIÓN}

CAPÍTULO PRIMERO: ¿Cómo es el sistema en Uruguay en cuanto a la explotación de los casinos?

\section{Sistema prohibitivo}

II. Como funciona este sistema

A. Régimen general de explotación de casinos.

A.1 Explotación de los casinos por medio de una concesión a un privado (municipal y nacional)

A.2 Explotación de los casinos a través del régimen mixto

A.3 Explotación de casinos directamente por el Estado.

A.4 Explotación de casinos por la Intendencia de Montevideo. 
B. Posibilidad de cobro de las deudas contraídas en casinos.

C. ¿Existen los controles adecuados por parte del Estado a los casinos?

C.1 Prevención de lavado de activos.

C.1.A Ley 19.754

C.1.B Decreto reglamentario 379/18

C.1.C. Conclusión

C.2 Ingreso de niños y adolescentes a espacios donde se realizan juegos de azar.

C.3 Controles en el marco de la normativa de humo.

C.4 Conductas problemáticas con el juego y programas de juego responsable.

C.4.A. Conductas problemáticas del juego.

C.4.B. Programas de juego responsable.

C.4.B.i Programa de un casino privado (Enjoy)

C.4.B.ii Programas de Casinos del Estado.

C.4.C. Conclusión.

D. Máquinas tragamonedas clandestinas.

D.1. Análisis de la sentencia del TCA No381 del 30 de septiembre de 2014.

D.2 Análisis de la comparecencia de Asociación Nacional de Juegos del Entretenimiento (ANJE) en la comisión de Hacienda del parlamento.

E. Proyecto de actualización de la normativa en Uruguay.

F. Juego On-line

F.1. Uruguay

F.2. Regulación del juego online en el extranjero

F.2.A. Reino Unido

F.2.B. Italia

F.2.C. Alemania 
F.2.D. Estados Unidos.

F.2.E. España

F.2.F. Colombia.

F.2.G. Argentina.

CAPÍTULO SEGUNDO: ¿Cómo está regulada la explotación de los casinos en los distintos países de la región?

I. Marco regulatorio del juego en Chile.
A. Régimen General
B. Juego online

II. Marco regulatorio del juego en Argentina.
A. Régimen General
B. Juego online

III. Marco regulatorio del juego en Brasil

CAPÍTULO FINAL. CONCLUSIÓN: ¿El sistema actual es el mejor para desarrollar la explotación de los casinos en Uruguay?

\section{APÉNDICES}
A. APÉNDICE NORMATIVO
B. BIBLIOGRAFÍA PROPUESTA

\section{IDENTIFICACIÓN DEL TEMA DE INVESTIGACIÓN}

En Uruguay existe un monopolio del Estado para la explotación de casinos, los cuales pueden ser desarrollados directamente por el Estado o a través de concesiones hacia los privados.

Si bien este es el marco legal actual y vigente a la fecha donde los distintos actores regulados han estado participando, desde hace unos años a esta parte ha surgido un actor que opera en paralelo a sistema. Estos son los operadores de máquinas tragamonedas clandestinas. Ellos se desarrollan al margen del sistema legal, instalándose en distintos tipos de comercios y bares a lo largo del país los cuales carecen de todo tipo de autorización, control y auditorías, así como tampoco ofrecen ningún tipo de garantías a los consumidores.

Los operadores autorizados se mueven dentro de un mercado regulado, velando por 
(entre otros): (i) el cumplimiento de las normas anti lavado; (ii) el cuidado y protección de los derechos del niño y adolescente; (iii) la realización de auditorías y controles tendientes a ofrecer las garantías necesarias a clientes y autoridades; y (iv) el pago de las regalías acordadas con el Estado y los respectivos impuestos. Por su parte, los operadores de máquinas clandestinas lo hacen al margen de toda la normativa vigente.

Por otro lado, el desarrollo de los juegos de azar ha ido evolucionando de la forma tradicional desarrollada en casinos, a nuevas modalidades de juego como el juego on-line. Esto ha tomado muchísima fuerza en aquellos países que lo ha regulado de forma acorde, abriendo un nuevo abanico de opciones para el desarrollo de este tipo de juegos de azar, siendo no solo una nueva realidad para los juegos de azar, sino el futuro de la industria.

De modo que se ha planteado la discusión si esta práctica monopólica del Estado es la apropiada, o si por el contrario se debe optar por una apertura del mismo, que sea manejado libremente por los privados y públicos, adecuando y aplicando los correspondientes mecanismos de control.

\section{CAPÍTULO PRIMERO ¿Cómo es el sistema en Uruguay en cuanto a la explotación de los casinos?}

\section{SISTEMA PROHIBITIVO}

La posibilidad de ejercer la explotación de casinos en Uruguay se encuentra reservada únicamente para el Estado. De modo que estamos frente a un sistema prohibitivo donde la posibilidad de ejercer la explotación de los juegos de azar con independencia del Estado se encuentra, valga la redundancia, prohibido.

Así surge de la normativa que rige en el tema y que se detalla a continuación:

- Ley $\mathrm{N}^{\mathrm{o}}$ 1595, de 16 de diciembre de 1882. "Ley $N^{0} 1595$ JUEGOS DE AZAR - Su prohibición. Artículo $1^{\circ}$.- Son absolutamente prohibidos los juegos de suerte o azar o de fortuna o en que intervenga envite, a excepción de la lotería y rifas públicas autorizadas por las Juntas Económico - Administrativas en conformidad a los reglamentos existentes o que se dictaren con acuerdo del Poder Ejecutivo.- Artículo $2^{\circ}$.- Los dueños de casas de juegos prohibidos por el artículo anterior o de establecimientos de cualquier naturaleza que lo permitan, incurrirán en multa de quinientos pesos, o en su defecto sufrirán seis meses de prisión con trabajos públicos. En este caso procederá además el decomiso de los objetos o utensilios destinados al juego. Artículo $3^{\circ}$.- A los individuos que concurran a dichas casas o establecimientos en el propio local en que se juegue, tomados en infraganti contravención, se les impondrá la multa de doscientos pesos a cada uno, y en su defecto dos meses de 
prisión con trabajos internos en las cárceles. Artículo $4^{\circ}$.- El producto de las multas que se cobrasen en virtud de esta Ley, se destinará única y exclusivamente a establecimientos de beneficencia en los departamentos donde se hagan efectivas. Artículo $5^{\circ}$.- Quedan en su fuerza y vigor todas las disposiciones del Código Rural, referentes a juegos prohibidos, en cuanto no se opongan directamente a la presente Ley. Artículo $6^{\circ}$.El P. Ejecutivo reglamentará la presente Ley. Artículo $7^{\circ}$.- Comuníquese, etc." (el subrayado me pertenece).

De modo que esta vieja Ley de 1882 que comenzó con la regulación en esta materia, ya incluía a texto expreso la prohibición de los juegos de azar.

Este principio fue reafirmado por toda la normativa siguiente que se ha ido desarrollando en nuestro país. Así fue que ciento treinta y cinco años después, con la sanción de la Ley de Rendición de cuentas del año 2017, Ley 19.535, la cual reafirma el principio rector de la ilicitud de los juegos de azar. Ésta establece en sus artículos 244 y 245 lo siguiente

"Artículo 244.- Declárese que la prestación de servicios a través de Internet, plataformas tecnológicas, aplicaciones informáticas o similares referidas a juegos de azar o apuestas on line, se encuentra alcanzada por el principio general de la ilegalidad previsto por el artículo 1 de la Ley 1.595, de 16 de diciembre de 1882, sin perjuicio, exclusivamente de la facultad conferida al Poder Ejecutivo por el artículo 19 de la Ley $N^{o}$ 17.453, de 28 de febrero de 2002, de organizar certámenes de pronósticos de resultados deportivos internacionales, así como de las habilitaciones específicas otorgadas por la autoridad competente hasta la fecha. Se interpreta que los juegos de casinos y salas, tales como póker, ruleta, slots, entre otros creados o a crearse, están absolutamente prohibidos en su modalidad a distancia (on line, virtuales o semejantes) y en cuanto a su modalidad presencial siguen vigentes las excepciones establecidas por la ley, así como las autorizaciones otorgadas de acuerdo a la misma".

"Art. 245.- Facúltese al Poder Ejecutivo a adoptar diversas medidas preventivas y sancionatorias para evitar la proliferación de actividades de comercialización de juego a través de Internet, en especial el bloqueo de acceso a sitios web, de flujos financieros, así como la prohibición de comunicaciones comerciales, patrocinio y publicidad de juegos no autorizados".

De modo que los citados artículos sirven para reflejar la ilegalidad de esta modalidad de juego de azar en nuestra norma.

Los artículos mencionados precedentemente fueron reglamentados por el Decreto $\mathrm{N}^{\mathrm{o}}$ 366/017, de fecha 21 de diciembre de 2017. Así, el art $1^{\circ}$ establece: 
Prohíbase toda prestación de servicios de juegos de azar o apuestas on line a través de internet, plataformas tecnológicas, aplicaciones informáticas o similares, que no cuenten con la autorización otorgada en forma previa y sin perjuicio de la facultad conferida al Poder Ejecutivo a través del artículo 19 de la ley 17.453, de 28 de febrero de 2002.

Los emisores de medios de pago electrónicos regulados por el Banco Central del Uruguay no podrán autorizar transacciones que impliquen la utilización de dichos instrumentos para efectuar pagos asociados a los juegos y apuestas a que refiere el inciso anterior. Tampoco podrán habilitar la utilización de los mencionados instrumentos para el cobro de premios originados en dichas actividades.

Lo previsto en el inciso precedente regirá a partir del $1^{\circ}$ de abril de 2018.

Art 2: La Dirección Nacional de Loterías y Quinielas será el organismo competente para vigilar el cumplimiento de lo previsto en el primer inciso del artículo precedente, pudiendo adoptar las medidas administrativas preventivas o sancionatorias necesarias a tal fin, actuando de oficio o a denuncia de un tercero.

A tales efectos, la mencionada Dirección relevará la existencia de sitios web en los que se presten servicios de juego de azar o apuestas on line no autorizados.

Art $3^{\circ}$ : Constatada la existencia de un sitio web en el cual se presten servicios de juego de azar o apuestas on line no autorizados, será instruido el expediente de investigación correspondiente y, previa vista a los interesados, en forma personal o a través de publicación de edictos, la Dirección Nacional de Loterías y Quinielas dictará resolución disponiendo el bloqueo de la dirección de dominio/uniform resource locator (URL).

El mero cambio de la dirección de dominio no hará necesario conferir nueva vista a los interesados.

Art $4^{\circ}$ : La resolución referida en el artículo precedente será comunicada a la Unidad Reguladora de Servicios de Comunicaciones, la que trasladará la orden de bloqueo a todos los operadores habilitados dentro del mercado nacional dentro del término de 48 horas. Dichos operadores deberán efectivizar el bloqueo dentro del término de 48 horas de recibida la comunicación por parte del organismo regulador.

Artículo 5: De disponerse de la información necesaria relativa a la entidad titular, la resolución referida precedentemente será también comunicada al Banco Central de Uruguay, el que trasladará la información que resulta de la misma a las instituciones emisoras de medios de pago electrónicos dentro del término de 48 horas. Los emisores deberán efectivizar las restricciones previstas en el artículo $1^{\circ}$ dentro del término de 48 horas de recibida la comunicación por parte del organismo regulador. 
Este decreto recoge buena parte de la Resolución de 09 de mayo de 2013 de la Dirección Nacional de Loterías y Quinielas donde justamente se establece en su artículo $10^{\circ}$ que: "queda prohibida la publicidad, patrocinio o promoción, bajo cualquier forma, de los juegos de suerte, envite o azar y la publicidad o promoción de los operadores de juego, cuando se carezca de la correspondiente autorización para la explotación y/o comercialización de juegos de titularidad estatal, y que se encuentren bajo la competencia y/o jurisdicción de esta Dirección Nacional."

Y en su artículo $11^{\circ}$ ) que establece que: "Queda prohibida la introducción de cualquier medio, incluso postal, con fines de expendio o a título gratuito, al igual que el anuncio, propaganda, circulación o venta, de todo otro concurso de pronósticos deportivos que no sean aquellos autorizados por la Dirección Nacional de Loterías y Quinielas."

También nuestro Código Penal en sus artículos 361 a 363 inclusive, se hace referencia a los juegos de azar catalogándolos como delitos de faltas. Estos establecen lo siguiente:

"Artículo 361: Será castigado con pena de 7 (siete) a 30 (treinta) días de prestación de trabajo comunitario: 1.- (Abuso de alcohol o estupefacientes).- El que en lugar público o accesible al público se presentare en estado de grave alteración psíquica o física producida por alcohol o estupefacientes, y el que por los mismos medios provocare en otros dicho estado. 2.- (Instigación a la mendicidad).- El que dedicare niños a mendigar públicamente. 3.- (Solicitud abusiva con acoso o coacción).- El que solicitare dinero o cualquier otro bien mediante actitudes coactivas o de acoso u obstaculizando o impidiendo de manera intencional el libre tránsito de personas a pie o en vehículo, por los espacios públicos. $\underline{4 .-}$ (Juego de azar).- El que en lugares públicos o accesibles al público, o en círculos privados de cualquier especie, en contravención de las leyes, tuviere o facilitare juegos de azar" (el subrayado me pertenece).

"Artículo 362 (Definiciones): Se considera juego de azar toda combinación en que la pérdida o la ganancia dependa totalmente o casi totalmente de la suerte, siendo el lucro el móvil que induce a tomar parte en ella. Se considera círculo privado al lugar concurrido por más de 6 personas para jugar, cualquiera que él fuere, incluso el que sirviere de habitación, no debiendo contarse, para fijar el número, los miembros integrantes de la familia".

"Artículo 363 (Confiscación preceptiva): Debe siempre procederse a la confiscación del dinero expuesto en el juego, así como de los muebles $o$ instrumentos destinados a él.

Por último, las obligaciones emanadas de los juegos de azar también se encuentran incluidas en nuestro Código Civil en sus artículos 2168 y siguientes. El mismo establece que:

Artículo 2168: El contrato de juego tendrá lugar, cuando dos o más personas poniéndose a jugar, se obligan a pagar a la que ganare, una suma de dinero u otro objeto determinado. 
Habrá apuesta cuando dos personas, que son de opinión contraria sobre cualquier materia, convienen que aquella cuya opinión resulte fundada, recibirá de la otra una suma de dinero o cualquier otro objeto determinado.

Se aplicará a la suerte las disposiciones de este capítulo, si a ella se recurre como apuesta o como juego.

Artículo 2169: La ley no acuerda acción alguna para reclamar lo ganado al juego o en apuesta. Exceptúanse los casos previstos en el artículo 2178.

Artículo 2170: La deuda de juego o apuesta no puede compensarse ni ser convertida por novación en una obligación civilmente eficaz.

Artículo 2171: El que hubiere firmado una obligación que tenía en realidad por causa una deuda de juego o de apuesta, conserva, a pesar de la indicación de otra causa civilmente eficaz, la excepción concedida por el artículo anterior y puede probar por todos los medios, la causa real de la obligación.

Artículo 2172: Si una obligación de juego o apuesta hubiere sido revestida como título a la orden, el que la suscribió debe pagarlo al portador de buena fe; pero tendrá acción para repetir el importe al que recibió el billete. La entrega de éste no equivaldrá a pago que hubiese hecho.

Artículo 2173: Tampoco hay acción alguna para reclamar el reembolso del dinero prestado a sabiendas para jugar o para apostar.

Artículo 2174: El que ha recibido y ejecutado el mandato de pagar sumas perdidas en el juego o apuesta, puede exigir del mandante el reembolso de ellas; pero si el mandato hubiese sido de jugar por cuenta del mandante o en sociedad de éste con el mandatario, no puede exigirse del mandante el reembolso delo anticipado por el mandatario.

Artículo 2175: El tercero que, sin mandato, hubiese pagado una deuda de juego o apuesta, no goza de acción alguna contra aquel por quien hizo el pago.

Artículo 2176 El que ha pagado voluntariamente deudas de juego o de apuestas no puede repetir lo pagado, a menos que hubiese dolo o fraude de parte del ganancioso. (Artículos 1313 y 1445).

Habrá dolo en el juego o apuesta, cuando el que ganó tenía certeza del resultado o empleó algún artificio para conseguirlo.

Artículo 2177: $\quad$ Lo pagado por las personas que no tienen la libre administración de sus bienes, podrá repetirse en todos los casos por sus representantes legales, no sólo de aquellos que ganaron, sino también de aquellos en cuya casa tuvo lugar el juego, siendo unos y otros considerados como deudores solidarios.

Artículo 2178: Las disposiciones precedentes no comprenden las deudas de juego o de apuesta que provengan de ejercicio de fuerza, destreza de armas, carreras y otros juegos o apuestas seme- 
jantes, los cuales producen acción civilmente eficaz, con tal que en ellos no se haya contravenido a alguna ley o reglamento de Policía.

En caso de contravención, desechará el Juez la demanda en el todo.

Artículo 2179: Cuando las personas se sirvieren del medio de la suerte, no como apuesta o juego, sino para dividir cosas comunes o terminar alguna cuestión, producirá, en el primer caso, los efectos de una partición; y en el segundo, los de una transacción, con tal que el convenio conste de un modo legal.

Artículo 2180: Lo dispuesto en este capitulo, se entiende que es sin perjuicio de lo que sobre el juego prescriba la ley penal.

Artículo 2181: Las loterías y rifas, cuando se permitan, serán regidas por disposiciones especiales o por los reglamentos de Policía.

Esto implica que las obligaciones que emanan como consecuencia de los juegos de azar pueden catalogarse de distinta manera, siendo algunas naturales, otras civiles y otras nulas.

Lo anterior, tal como se ahondará más adelante, dependerá de si los juegos de azar se desarrollan fuera del marco legal permitido o no. Siendo los que se encuentran enmarcados dentro de la legalidad, a mi entender, obligaciones civiles.

\section{COMO FUNCIONA ESTE SISTEMA PROHIBITIVO}

\section{A. Régimen General de explotación de los casinos}

La explotación de juegos de azar en Uruguay es realizada a través del Estado (Poder Ejecutivo) o por el Gobierno Departamental de Montevideo.

El Estado o la Intendencia Municipal de Montevideo pueden desarrollar y explotar la actividad de casinos ya sea de forma directa, bajo la forma de concesión o a través de un régimen mixto.

Esto último se desprende del Artículo 20 del decreto Ley 14.335 de 1974, el cual autoriza al Estado a desarrollar la actividad de casino ya sea directamente, bajo un régimen de concesión o a través de una autorización directa a un privado. Con relación a estas últimas, no existen antecedentes de haber sido otorgadas.

Por su parte, la Ley 10.709 de 1946 autoriza a la Intendencia Municipal de Montevideo (IMM) a desarrollar la actividad de casinos en hoteles propiedad de ésta. La Constitución de la República reforzando esta posición, consagra en su artículo 297 que dentro de los ingresos de los gobiernos municipales, se encuentran los beneficios de la explotación de casinos.

Adicionalmente la Constitución en su Artículo 273 otorga a los Gobiernos Departamentales a través de la Junta, el poder de otorgar concesiones sobre servicios públicos en su respectiva jurisdicción. 
Actualmente en Uruguay existen dos casinos privados en régimen de concesión. Uno que opera en el país en la ciudad de Punta del Este desde el año 1997 y otro en el barrio de carrasco en Montevideo.

El marco legal aplicable a este tipo de explotaciones, se rige por el decreto 588/975, reglamentario del DL 14.335 y sus modificaciones, regulan la concesión de casinos del Estado. Adicionalmente, este decreto también regula el proceso licitatorio para la selección de concesionarios.

El artículo 20 del Decreto Ley 14.335 establece lo siguiente:

"El Estado explotará los casinos de que dispone actualmente y las salas de juego que estime conveniente instalar, mediante el régimen de concesiones.

La elección del concesionario se hará mediante pedido de ofertas, teniendo en cuenta para la adjudicación entre otros elementos y requisitos, el precio de la concesión, los antecedentes y solvencia del ofertante, el monto de las inversiones, bienes que se incorporarán al patrimonio nacional o estatal y los planes de desarrollo turístico y fomento local o nacional.

Mientras no se otorguen las concesiones se podrá explotar directamente o mediante autorizaciones de acuerdo con la reglamentación que establezca el Poder Ejecutivo".

Por su parte, El decreto 588/975 indica a resumidas cuentas lo siguiente:

"Artículo 2 (Zonas de interés nacional). - Se considera de interés nacional la explotación de juegos de azar de Casinos en las siguientes zonas balnearias, termales o de interés turístico: Punta del Este, Piriápolis, Atlántida, zona costera de Rocha, Departamento de Colonia, zona termal del litoral noroeste de la República y Rivera.

Artículo 3: (Privatización de los Casinos). - Los Casinos instalados o a instalarse en el territorio nacional serán explotados por el Estado mediante el régimen de concesiones acordadas a particulares. Las concesiones serán otorgadas por el régimen de Licitación Pública.

Artículo 4: (Requisito para obtener la concesión). - Será requisito indispensable para obtener la concesión de explotación de juegos de azar en Casinos, así como para gozar de los eventuales beneficios pactados en aplicación de la Ley de Promoción Industrial 14.178 de 28 de marzo de 1974 modificada por el artículo 31 de la ley 14.335 (inciso E) del artículo $4^{\circ}$ ), la construcción de sendos establecimientos hoteleros $u$ otros centros de atracción turística en la localidad, que deberán 
estar en consonancia con la categoría internacional incluyendo obras de infraestructura y otros elementos o servicios indispensables para su explotación. Los establecimientos hoteleros deberán tener como mínimo las comodidades y servicios exigidos para las categorías cinco estrellas $y$ cuatro estrellas.

El Poder Ejecutivo determinará en cada caso, el mínimo de habitaciones que deberán tener los establecimientos hoteleros, en atención al volumen de la inversión y al máximo de unidades de juego permitidas. Si se tratare de un complejo turístico diverso del hotelero, el monto de su construcción será por lo menos equivalente al necesario para la construcción de los complejos hoteleros detallados anteriormente en sus respectivas categorías.

Artículo 13: (Exigencias del llamado a licitación). - Sin perjuicio de las exigencias que correspondan en cada caso, el llamado a licitación determinará además:

a) La zona donde deberá construirse el Hotel Casino o el centro de atracción turística al que se integra.

b) Las características y comodidades de los establecimientos propios para el nivel internacional teniendo en cuenta que las instalaciones destinadas a Casinos tengan sus accesos y servicios propios e independientes del cuerpo en sí de las instalaciones hoteleras o turísticas vecinas.

c) Las sumas bases que el concesionario deberá abonar anualmente al Estado, por la explotación y garantía correspondiente a depositar. Estos importes se determinarán de acuerdo con el número y tipo de artefactos o unidades de juego autorizados a utilizar en el contrato de concesión.

d) Criterios cuantitativos que se utilizarán para ajustar anualmente las sumas a abonar o depositar.

e) Los juegos que están autorizados, teniendo en cuenta que no se podrán autorizar juegos de cartas en base a destreza."

Y en esta misma línea el decreto sigue indicando entre otros, límite de cantidad de máquinas, porcentaje de empleados uruguayos a contratar, obligaciones, sanciones, entre otros.

"Artículo 14: (Límite máximo de unidades de juego). - El contrato de concesión fijará el límite máximo de unidades de juego. El Poder Ejecutivo podrá autorizar hasta el 20\% de aumento sobre dicho límite cuando considere que la capacidad turística de la zona así lo aconseja. Por encima del citado porcentaje se deberá pactar una nueva inversión de interés turístico proporcional a la extensión solicitada. 
Artículo 16: (Requisitos del personal utilizado). - El 80\% del personal utilizado en el funcionamiento del complejo turístico deberá ser ciudadano natural o legal uruguayo.

Artículo 17: (Obligaciones del concesionario). - El Contrato de concesión obligará al concesionario a cumplir estrictamente con los términos de la misma, debiendo realizar la explotación con total normalidad y regularidad. Deberá cumplir en tiempo y forma con las obras previstas, etapa por etapa.

Artículo 18: (Sanciones). - Toda contravención legal o reglamentaria así como el incumplimiento de las condicionantes del contrato dará lugar a una sanción que podrá ser de carácter pecuniario o de cierre del Casino, pudiendo esta, si la falta así lo indicara, ser permanente perdiendo la concesión de acuerdo a lo dispuesto en el Capítulo VII de la ley 14.335 de 23 de diciembre de 1974.

Por otro lado, tal como fue indicado precedentemente el artículo 273 de la Constitución es aplicable para los casos de concesión de gobiernos municipales, tales como la Intendencia Municipal de Montevideo. Este artículo indica lo siguiente:

\section{SECCION XVI - DEL GOBIERNO Y DE LA ADMINISTRACION DE LOS DEPAR- TAMENTOS}

\section{CAPITULO III}

Artículo 273: $\quad$ La Junta Departamental ejercerá las funciones legislativas y de contralor en el Gobierno Departamental.

Su jurisdicción se extenderá a todo el territorio del departamento.

Además de las que la ley determine, serán atribuciones de las Juntas Departamentales:

$\left.1^{\circ}\right)$ Dictar, a propuesta del Intendente o por su propia iniciativa, los decretos y resoluciones que juzgue necesarios, dentro de su competencia.

$2^{\circ}$ ) Sancionar los presupuestos elevados a su consideración por el Intendente, conforme a lo dispuesto en la Sección XIV.

$3^{\circ}$ ) Crear o fijar, a proposición del Intendente, impuestos, tasas, contribuciones, tarifas y precios de los servicios que presten, mediante el voto de la mayoría absoluta del total de sus componentes.

$\left.4^{\circ}\right)$ Requerir la intervención del Tribunal de Cuentas para informarse sobre cuestiones relativas a la Hacienda o a la Administración Departamental. El requerimiento deberá formularse siempre que el pedido obtenga un tercio de votos del total de componentes de la Junta.

$\left.5^{\circ}\right)$ Destituir, a propuesta del Intendente y por mayoría absoluta de votos del total de componentes, los miembros de las Juntas Locales no electivas. 
$\left.6^{\circ}\right)$ Sancionar, por tres quintos del total de sus componentes, dentro de los doce primeros meses de cada período de Gobierno, su Presupuesto de Sueldos y Gastos y remitirlo al Intendente para que lo incluya en el Presupuesto respectivo. Dentro de los cinco primeros meses de cada año podrán establecer, por tres quintos de votos del total de sus componentes, las modificaciones que estimen indispensables en su Presupuesto de Sueldos y Gastos.

$\left.7^{\circ}\right)$ Nombrar los empleados de sus dependencias, corregirlos, suspenderlos y destituirlos en los casos de ineptitud, omisión o delito, pasando en este último caso los antecedentes a la Justicia.

$\left.8^{\circ}\right)$ Otorgar concesiones para servicios públicos, locales o departamentales, a propuesta del Intendente, y por mayoría absoluta de votos del total de sus componentes.

$\left.9^{\circ}\right)$ Crear, a propuesta del Intendente, nuevas Juntas Locales.

10) Considerar las solicitudes de venia o acuerdo que el Intendente formule.

11) Solicitar directamente del Poder Legislativo modificaciones o ampliaciones de la Ley Orgánica de los Gobiernos Departamentales.

Adicionalmente, todo lo referente al proceso licitatorio se encuentra regulado bajo el Texto Ordenado de Contabilidad y Administración Financiera y Normas Concordantes y Complementarias (TOCAF).

Por lo que conforme lo establece la normativa vigente (decreto ley 14.335) autoriza al Estado a explotar directamente un casino, sin necesidad de ningún acto legislativo. Por el contrario, para el caso de un privado, es necesaria una resolución del Poder Ejecutivo dando inicio a una licitación pública en orden de seleccionar a un concesionario (conforme lo exige el 588/1975). Por otro lado, el Gobierno Municipal requiere un acto legislativo emanado de la Junta para conceder la concesión. Tal acto es el requerido para dar inicio al proceso licitatorio en estos casos.

En el caso particular del casino privado que opera en la ciudad de Montevideo, tuvo una normativa específica, la Ley 18.231 la cual estableció en sus dos artículos lo siguiente

Art 1.- $\quad$ Autorizase a la Intendencia Municipal de Montevideo a convocar a una licitación pública internacional cuyo objeto incluya la concesión de la gestión de la sala de juegos del casino municipal que funciona en el Hotel Casino Carrasco, por un plazo de treinta años, debiendo el adjudicatario abonar un canon o precio.

Art 2.- $\quad$ Sin perjuicio de las competencias asignadas al Banco Central del Uruguay y al Poder Ejecutivo a través del Ministerio de 
Economía y Finanzas en el marco de lo dispuesto por la Ley $N^{\circ} 17.835$, de 23 de setiembre de 2004, y su reglamentación, corresponderá a la Intendencia Municipal de Montevideo el contralor de los juegos de azar que se desarrollen en el establecimiento, de acuerdo al proceso licitatorio referido en el artículo anterior.

Como fue mencionado precedentemente, el TOCAF contiene toda la regulación general para los llamados a licitación, tanto sea para llamados realizados por el Estado como por Gobiernos Departamentales.

Este texto ordenado, además de regular los distintos aspectos del proceso licitatorio, rige determinados principios rectores procurando respetar derechos básicos de los oferentes tales como: (i) igualdad entre los oferentes; (ii) transparencia en cada etapa del proceso; (iii) publicidad de toda información relativa a la licitación; y (iv) concurrencia de la mayor cantidad de oferentes posibles.

Adicionalmente, la regulación específica (términos y condiciones) para cada llamado en particular se encuentra incluida en los pliegos de condiciones.

Los pliegos son los documentos más importantes en una licitación pública ya que regulan aspectos relevantes tales como: (a) descripción del proyecto (tamaño de la inversión) y condiciones de la oferta; (b) requisitos que los oferentes deben cumplir (solvencia económica, comercial, antecedentes en proyectos similares, etc.); (c) pasos concretos a seguirse en este proceso licitatorio puntual; (d) garantías que los oferentes deben presentar en cumplimiento de las obligaciones establecidas en el pliego y en el contrato.

Una vez finalizado el proceso licitatorio donde uno de los oferentes es seleccionado por la Administración, el contrato de concesión deberá ser suscripto.

De modo que tanto el pliego de condiciones como el contrato de concesión son los documentos que regulan los principales aspectos de la concesión a un privado.

Con relación al contrato de concesión, mucho se ha escrito. Si pudiéramos hacer un brevísimo resumen de los principales aspectos del mismo serían los siguientes:

- Intuito personae: los derechos y obligaciones que emanan del contrato de concesión no pueden ser cedidos por el concesionario sin la autorización por escrito de la autoridad.

- Plazo determinado: de acuerdo con lo establecido por el Artículo 51 de la Constitución, un contrato de concesión no puede ser por tiempo indefinido.

- Exclusividad/ Protección: Las actividades desarrolladas bajo un contrato de concesión son normalmente realizadas bajo exclusividad. En línea de lo anterior, la Administración puede obligarse a no otorgar nuevas concesiones siempre que no cumplan con determinadas condiciones acordadas (por ej: determinado monto de inversión).

- Terminación: prevé las causales a través del cual el contrato puede ser rescindido. 
- Por último, también existen determinadas normas específicas las cuales un posible interesado en acceder a la explotación de un casino privado por medio de una concesión pública puede ampararse. Esto se encuentra regulado en la Ley 17.555, conocida como la Ley de reactivación Económica, la cual otorga la posibilidad a través de sus artículos 19 y 20 de ampararse bajo el beneficio de iniciativa privada.

Este fue el caso de la solicitud de un oferente quien solicitó ampararse bajo este beneficio a los efectos de obtener la concesión de una licencia para operar un casino en la ciudad de Punta del Este.

Este oferente, en caso de ser seleccionado para realizar un resort \& casino, deberá dar cumplimiento a lo establecido en el contrato de concesión del otro casino privado que opera en esa misma ciudad, debiendo superar los umbrales de inversión establecidos.

\section{A.2 Explotación de los casinos a través del régimen mixto}

El régimen mixto de explotación surgió a partir del decreto 63/997 el cual fue complementado por el decreto 488/08 y posteriormente por el 302/2009.

En estos últimos se estableció a través de la redacción en su artículo 37, lo siguiente:

Artículo 37: La integración de Salas de Juego al Sistema Mixto de Explotación, Asociadas a Complejos Turísticos, Comerciales, Deportivos y/o Culturales, sean nuevas o ya explotadas bajo el Sistema Tradicional, se regulará por las siguientes normas, sin perjuicio de la facultad conferida al Ministerio de Economía y Finanzas por el artículo 18 del Decreto $N^{o} 455 / 007$, de 26 de noviembre de 2007.

37.1.- En cada caso, la Dirección General de Casinos del Estado realizará los procedimientos administrativos que correspondan, atendiendo a razones de oportunidad o conveniencia y de acuerdo a las normas legales y reglamentarias vigentes, debiéndose tener en cuenta, a los efectos de la evaluación de las ofertas de los interesados, los siguientes aspectos:

37.1.1.- Documentación jurídica del oferente que acredite su existencia, vigencia y representación.

37.1.2.- Información económico-financiera del oferente en cuanto a su solvencia, así como en cuanto a su disponibilidad de financiamiento y el origen de los fondos que se destinarán a la inversión propuesta. (Situación y respaldo financiero que, a juicio de la Administración, aseguren el cumplimiento de las obligaciones y responsabilidades a asumir durante el plazo de vigencia del contrato a ser suscripto).

37.1.3.- Experiencia en emprendimientos comerciales, turísticos o de otra índole cuya significación económica y éxito empresarial sea relevante a efectos de considerar los antecedentes del oferente y sus integrantes.

37.1.4.- Plan de desarrollo arquitectónico del proyecto y su entorno.

37.1.5.- Plan de negocios para la inversión a realizar y para la Sala de Juego, incluyendo la estimación fundamentada del ingreso que tendrá la Dirección General de Casinos del Estado por 
la explotación de la Sala de Juego en función del plan de negocios, y en función de la contraprestación pretendida por el inversor.

37.1.6.- Impacto económico, social, cultural, sobre el empleo y la descentralización, entre otros, del emprendimiento que pretende desarrollar el inversor, así como de la Sala de Juego.

37.2.- En caso de tratarse de Salas de Juego y/o Casino asociadas a proyectos de alojamiento turístico, el mismo deberá ser categorizado por el Ministerio de Turismo y Deporte como de al menos cuatro estrellas, según lo dispuesto por el Decreto $N^{\circ}$ 384/997, de 15 de octubre de 1997.

En todos los casos de Complejos Turísticos el oferente deberá obtener la conformidad del Ministerio de Turismo y Deporte respecto del mismo.

37.3.- La Dirección General de Casinos del Estado elaborará y mantendrá actualizado un instructivo informativo sobre las metodologías de evaluación y la información o documentación requerida a los oferentes o interesados.

37.4.- Las iniciativas privadas vinculadas con Salas de Juego que presenten los particulares al amparo de los artículos 19 y 20 de la Ley $N^{o}$ 17.555, de 18 de setiembre de 2002, su Decreto Reglamentario $N^{o} 442 / 002$, de 28 de setiembre de 2002 y demás normas aplicables, así como los casos comprendidos en el inciso segundo del artículo 18 de Decreto $N^{\circ} 455 / 007$, de 26 de noviembre de 2007, serán evaluadas en base a los aspectos indicados en el 37.1.

37.5.- Con el cometido de dictaminar o informar sobre las propuestas recibidas, funcionarán una o más Comisiones Asesoras que estarán integradas por representantes de los Ministerios de Economía y Finanzas y de Turismo y Deporte, invitándose a participar a un representante del Gobierno Departamental respectivo.

37.6.- A los efectos de la contratación, la Dirección General de Casinos del Estado deberá tener en cuenta que:

37.6.1.- Sin perjuicio de los dictámenes e informes elaborados por la Comisión Asesora y en forma previa a la aceptación de cualquiera de las ofertas realizadas, la Dirección General de Casinos del Estado analizará los ingresos esperados para sí y para el inversor por la explotación de la Sala de Juegos en función del plan de negocios y la contraprestación ofrecida por el inversor y lo someterá a consideración del Ministerio de Economía y Finanzas para que el mismo evalúe la relación entre los ingresos esperados y el monto y características de la inversión comprometida por el inversor.

37.6.2.- El Poder Ejecutivo efectuará la adjudicación a la oferta que considere más conveniente, apreciando el dictamen de la Comisión Asesora, pudiendo también declarar desierto el procedimiento, o rechazar las ofertas en forma total o parcial. La celebración del respectivo contrato estará a cargo de la Dirección General de Casinos del Estado.

37.6.3.- En el caso que la Sala de Juego en cuestión sea un Casino que para su incorporación requiera contar con autorización legal, la prosecución del procedimiento y la efectiva integración de la Sala de Juego al Sistema Mixto quedarán sujetos, sin perjuicio de los dictámenes e informes, 
a la sanción y promulgación de las normas correspondientes.

37.6.4.- En ningún caso se podrá habilitar la Sala de Juegos con anterioridad a la apertura al público del sector del Complejo destinado a la actividad turística, comercial, deportiva y/o cultural, de acuerdo con lo comprometido.

37.6.5.- A los efectos de formalizar la integración de la Sala de Juegos al Sistema Mixto de Explotación y fijar las normas sobre las cuales se regirá la relación entre el oferente seleccionado y la Dirección General de Casinos del Estado, éstos suscribirán el contrato de arrendamiento y de servicios de adhesión que elaborará la Dirección General de Casinos del Estado. El contrato será suscripto en escritura pública, teniéndose presente que en ninguna circunstancia entre el inversor y el Estado se crea vinculación societaria alguna.

37.7.- En cumplimiento del artículo 211, literal B) de la Constitución de la República, deberá darse intervención previa al Tribunal de Cuentas de la República de todo lo actuado.

37.7.1.- Previo a la firma del contrato con la Dirección General de Casinos del Estado y a satisfacción de ésta, el inversor deberá:

i. Acreditar que posee legitimación sobre el o los inmuebles que será asiento de la inversión proyectada y de la Sala de Juego.

ii. Constituir una garantía especial de cumplimiento de su obligación preliminar de entrega del local arrendado a la Dirección General de Casinos del Estado en condiciones de funcionamiento para el destino pactado.

El inversor deberá constituir una garantía de fiel cumplimiento del contrato una vez que esté en condiciones de entregar el inmueble arrendado a la Dirección General de Casinos del Estado.

37.7.2.- En cada procedimiento administrativo de contratación, la Dirección General de Casinos del Estado fijará las normas particulares sobre montos, plazos, oportunidades para su constitución y ejecución, contenido, etc., que deberán observarse respecto de las dos garantías mencionadas anteriormente.

37.8.- Los costos de cualquier índole ocasionados o derivados de la preparación, formulación y presentación de la propuesta, y todos los demás trámites derivados de la misma o relacionados con la pretendida contratación, aun cuando ésta quedare sin efecto, no generan derecho a reclamo alguno del oferente por indemnización, pérdida de oportunidad u otras circunstancias.

Al respecto, el Dr. Delpiazzo 3 indicó con precisión que este régimen "surge como un sistema de explotación público privada, consistente en la apertura y explotación de salas de juego por parte del Estado, como complemento a inversiones privadas en materia turística y/o comercial, para lo cual se habilita al inversor a arrendar al Estado el inmueble correspondiente, los muebles necesarios y los servicios periféricos adecuados, a cambio de un precio determinados en función de los resultados de la gestión de sala."

3 Carlos E. Del Piazzo, Derecho Administrativo Especial Vol 2, pag 524-525. 
Por lo que básicamente podemos decir que a través de esta forma de explotación, el Estado capta la inversión privada para la refacción, mantenimiento y seguridad de la sala, conservando para si la explotación directa del juego que permanece en manos del Estado.

A la fecha, a través de este tipo de explotación de juegos de azar, existen cuatro casinos y ocho salas de esparcimiento.

\section{A.3. Explotación de los casinos directamente por el Estado}

A la luz de la normativa analizada podemos afirmar que esta es la regla. En Uruguay se rige por un modelo prohibitivo, salvo que el mismo sea desarrollado o explotado directamente por el Estado.

Al respecto, Augusto Durán Martínez establece lo siguiente: “Es obvio que la actividad de casinos no es inherente al Estado, por lo que no es un cometido esencial del Estado. Tampoco se puede decir que el Estado asuma esa actividad para satisfacer necesidades colectivas impostergables, por lo que no es un servicio público. No reúne características de los servicios sociales y admite ser monopolizada, por lo que no configura un servicio social. No queda, así, otra alternativa, que considerarla una actividad privada a cargo del Estado. Una actividad que el Estado en determinado momento consideró, por razones de interés general, necesario asumir, y hacerlo en régimen de monopolio. ${ }^{4}$

A través de este sistema, el Estado explota los juegos de azar a través de la Dirección General de Casinos.

Esta entidad no solo tiene a su cargo la explotación la explotación de los juegos de azar (ya sea directa o a través del régimen señalado en el capítulo anterior - mixto-), sino que también tiene a su cargo la detección del juego ilícito y la promoción de la actividad hípica a nivel nacional.

Lo anterior surge de la siguiente normativa:

- Ley $N^{o}$ 13.921, de 30/11/70 (art. 1 en la redacción dada por el art. 327 del Decreto - Ley $N^{\circ}$ 14.189, de 30/04/74): "Facúltese al Poder Ejecutivo para explotar directamente juegos de azar en hasta nueve Casinos instalados o a instalar en los Departamentos de Maldonado, Rocha, Colonia, Rivera, Canelones y en la zona termal del noroeste de la República. El Poder Ejecutivo determinará, dentro de los límites territoriales establecidos, el lugar, período y condiciones de funcionamiento de cada Casino, atendiendo especialmente a aquellas zonas o centros que se estimen aptos para el fomento y desarrollo del turismo receptivo de carácter internacional".

- Ley $N^{o} 15.206$, de 3/11/81 (art. 4): "Extiéndase la facultad otorgada al Poder Ejecutivo por la ley 13.921, de 30 de noviembre de 1970, a los casinos que se instalen en hoteles de categoría internacional "cinco estrellas", cuya actividad haya sido declarada de interés nacional al amparo de la ley 14.178, de 28 de marzo de 1974".

4 Estudios de Derecho Administrativo - No13 - Año 2016. Máquinas tragamonedas, Augusto Duran Martínez. Pag 11. 
- Ley $N^{o}$ 17.296, de 21/01/01 (art. 181): "Facúltese al Poder Ejecutivo a autorizar a la Dirección General de Casinos a contratar al personal minimo imprescindible a los efectos de cubrir las necesidades que generen las nuevas salas con cargo a los fondos de libre disponibilidad de esta Unidad Ejecutora".

- Decreto $N^{\circ} 63 / 997$, de 4/03/97 (capítulo II)

- Ley 18.719, de 27/10/10 (art. 321). "Facúltese al Ministerio de Economía y Finanzas, por intermedio de la Dirección General de Casinos, a promover la actividad hípica a nivel nacional y la supervisión del juego de apuestas mutuas, en todas sus modalidades, sobre el resultado de carreras de caballo en los hipódromos reconocidos en forma expresa por dicha Dirección, pudiendo a tales efectos disponer las medidas que estime necesarias incluyendo, entre otras, requerir informes, auditorias, inspecciones e intervenciones contables"

A la fecha, a través de este sistema el Estado explota dos casinos y diecisiete salas de esparcimiento.

\section{A.4. Explotación de los casinos por la Intendencia de Montevideo}

Como mencionado anteriormente, la posibilidad de que sea la propia Intendencia de Montevideo la que explote los casinos, surge de la Ley 10.709 y del artículo 297 de la Constitución de la República.

Así, el artículo $6^{\circ}$ de la Ley 10.709 establece en su artículo $6^{\circ}$ lo siguiente:

Con destino a la formación del fondo previsto por el artículo anterior, se crean los siguientes impuestos:

A) Salas de teatros, conciertos y circos.

El impuesto será del $4 \%$ en las entradas fijadas hasta $\$ 1.50 .\left(^{*}\right)$

De un peso cincuenta y un centésimos (\$1.51) a tres pesos (3.00) de costo, el impuesto será de diez por ciento $(10 \%)$ por cada entrada. trada.

De tres pesos un centésimo (\$3.01) en adelante, el quince por ciento (15\%) por cada en-

Salas de cines: \$ 0.01 cuando el valor de entrada sea hasta de \$ 0.30; \$ 0.02, cuando el valor de entrada sea hasta \$0.40; y \$0.3, cuando el valor de entrada sea hasta de \$0.50, cualquiera sea el régimen de función. $(*)$

De cincuenta y un centésimos (\$ 0.51) a un peso (\$1.00), el diez por ciento (10\%).

De más de un peso (\$1.00), el quince por ciento (15\%) por cada entrada.

B) $\left({ }^{*}\right)$

C) Carreras: el impuesto será de \$0.20 por persona. $\left(^{*}\right)$ 
El Jockey Club de Montevideo, en sustitución del impuesto a las entradas al circo, entregará la suma de \$ 1.000 .00 mensuales. Cuando el dividendo que pague un caballo sea mayor de \$ 10.00 , pagará \$ 1.00 por cada \$ 10.00 o fracción mayor de \$ 5.00 de exceso sobre \$10.00. Estos impuestos no los pagarán las instituciones y entidades que entreguen al Estado, por cualquier concepto y por cualquier término, una cantidad mayor de \$200.000.00 anuales.

D) Bailes de carnaval: entrada al espectáculo el 10\%, bailes en general en que se cobre entrada el $5 \%$.

E) Los casinos de juegos explotados por particulares, además de los porcentajes ya establecidos, entregarán el $20 \%$ del producto total de los juegos autorizados, deducidos los gastos de administración.

Los casinos municipales, además de los porcentajes ya establecidos, contribuirán con el 10\% del producto total de los juegos, deducidos los gastos de administración.

Modifícase el artículo $4^{\circ}$ de la ley número 5.352, y autorizase al Municipio de Montevideo para explotar en los hoteles balnearios de su propiedad, los juegos habituales en los casinos. (el resaltado me pertenece)

F) Dancings, cabarets, casas de bailes públicos, boites y similares: el 10\% del producto diario. (*) La Comisión Honoraria queda facultada para fijar previos estudios del caso la contribución minima diaria de cada establecimiento.

Los impuestos a que se refiere este artículo se recaudarán por las oficinas nacionales o departamentales a quienes les corresponda autorizar o administrar esos espectáculos y fiscalizar la expedición de las entradas. La recaudación y fiscalización se efectuará conforme a las reglamentaciones que se dicten. Sin perjuicio de esto el Ministerio de Salud Pública dispondrá los controles que crea pertinentes por intermedio de sus funcionarios inspectivos.

Las sumas recaudadas de acuerdo con esta ley a medida que se vayan percibiendo por la oficina correspondiente, serán depositadas en el Banco de la República Oriental del Uruguay, en cuenta especial y a la orden del Ministerio de Salud Pública.

Por su parte, el artículo 297 de la Constitución establece que:

Serán fuentes de recursos de los Gobiernos Departamentales, decretados y administrados por éstos:

$\left.1^{\circ}\right)$ Los impuestos sobre la propiedad inmueble, urbana y suburbana, situada dentro de los limites de su jurisdicción, con excepción, en todos los casos, de los adicionales nacionales establecidos o que se establecieren. Los impuestos sobre la propiedad inmueble rural serán fijados por el Poder Legislativo, pero su recaudación y la totalidad de su producido, excepto el de los adicionales establecidos o que se establecieren, corresponderá a los Gobiernos Departamentales respectivos. La cuantía de los impuestos adicionales nacionales, no podrá superar el monto de los impuestos con destino departamental. 
$2^{\circ}$ ) El impuesto a los baldíos y a la edificación inapropiada en las zonas urbanas y suburbanas de las ciudades, villas, pueblos y centros poblados.

$3^{\circ}$ ) Los impuestos establecidos con destino a los Gobiernos Departamentales y los que se creen por ley en lo futuro con igual finalidad sobre fuentes no enumeradas en este artículo.

$\left.4^{\circ}\right)$ Las contribuciones por mejoras a los inmuebles beneficiados por obras públicas departamentales.

$\left.5^{\circ}\right)$ Las tasas, tarifas y precios por utilización, aprovechamiento o beneficios obtenidos por servicios prestados por el Gobierno Departamental, y las contribuciones a cargo de las empresas concesionarias de servicios exclusivamente departamentales.

$\left.6^{\circ}\right)$ Los impuestos a los espectáculos públicos con excepción de los establecidos por ley con destinos especiales, mientras no sean derogados, y a los vehículos de transporte.

$\left.7^{\circ}\right)$ Los impuestos a la propaganda y avisos de todas clases. Están exceptuados la propaganda y los avisos de la prensa radial, escrita y televisada, los de carácter político, religioso, gremial, cultural o deportivo, y todos aquellos que la ley determine por mayoría absoluta de votos del total de componentes de cada Cámara.

$8^{\circ}$ Los beneficios de la explotación de los juegos de azar, que les hubiere autorizado o les autorice la ley, en la forma y condiciones que ésta determine.

$\left.9^{\circ}\right)$ Los impuestos a los juegos de carreras de caballos y demás competencias en que se efectúen apuestas mutuas, con excepción de los establecidos por ley, mientras no sean derogados.

10) El producido de las multas:

a) que el Gobierno Departamental haya establecido mientras no sean derogadas, o estableciere según sus facultades;

b) que las leyes vigentes hayan establecido con destino a los Gobiernos Departamentales;

c) que se establecieran por nuevas leyes, con destino a los Gobiernos Departamentales.

11) Las rentas de los bienes de propiedad del Gobierno Departamental y el producto de las ventas de éstos.

12) Las donaciones, herencias y legados que se le hicieren y aceptare.

13) La cuota parte del porcentaje que, sobre el monto total de recursos del Presupuesto Nacional, fijará la Ley Presupuestal.

Por último, en lo referente a los reglamentos de funcionamiento, normas aplicables al personal, sistema de control interno, control de CCTV y capacitaciones, se encuentra regido por el Volumen IX del Digesto municipal, "CASINOS DEPARTAMENTALES". 


\section{B. Posibilidad de cobro de las deudas contraídas en casinos}

Mucho se ha escrito con relación a este tema. Por un lado, la doctrina tradicional encabezada por Gamarra, Peirano, De Cores y Berdaguer quienes entienden que la regulación del Código Civil aplica en todos los casos, aun cuando la explotación de los casinos sea realizada por parte del Estado o exista una autorización administrativa (concesión) a favor de un privado para explotar juegos de azar. Por lo tanto, para ellos la autorización estatal para explotación de los juegos de azar no modifica la naturaleza de las obligaciones asumidas, sino que tiene por objeto eliminar la ilicitud de carácter penal.

Desarrollos doctrinarios más recientes sostienen que casinos explotados por el Estado (ya sea directamente o bajo el régimen de concesión) quedarían enmarcados en lo establecido por 2181 del Código Civil ("Las loterías y rifas, cuando se permitan, serán regidas por disposiciones especiales o por los reglamentos de Policía"). En esta línea el argumento central de esta corriente doctrinaria, estaría basado en la incongruencia en que por un lado el Estado autoriza al desarrollo de los juegos de azar, y por otro lado les quita la protección que tienen las obligaciones civiles.

Dentro de esta posición, a la cual me afilio, sigue la misma línea de aquellos países donde el juego es legal. En Uruguay, encontramos a autores como Szafir y Doval quienes han establecido: "nadie apostaría sabiendo que en caso de ganar, su deudor asume una obligación natural" y que por lo tanto sería de aplicación el artículo 2181 del CCU citado precedentemente, no siendo de aplicación las normas del Código Civil que regulan las deuda de juego. Siguiendo esta línea, de que estas obligaciones son civiles y no naturales, también establecen que la relación entre cliente y casino se encuentran enmarcadas en la ley de defensa del consumidor, Ley 17.250.

Este mismo razonamiento es seguido por Beatriz Venturini ${ }^{5}$, quien en su muy completo trabajo donde afirma que: "en nuestro ordenamiento es dable afirmar que el juego y apuesta se presentan en tres variantes con sus respectivas respuestas jurídicas:

- Juego común: genera obligaciones naturales

- Juego deportivo: genera obligaciones civiles; y

- Juego prohibido: nulo."

Una vez establecido lo anterior, desarrolla a mi entender, correctamente como se encuentran regidas las obligaciones que contrae el Estado en contratos de juego y apuesta.

En esta línea ella establece que "si se entiende que juego permitido es todo aquel juego de azar que organice el Estado (o un particular debidamente autorizado por el Estado) deberemos analizar las normas especiales fuera del Código Civil. Y ninguna de las normas especiales remite a este capítulo del Código Civil ni habla de obligaciones naturales".

En esta línea, ella menciona que por el "giro lingüístico empleado, parece desprenderse que no estamos ante obligaciones naturales". Muy por el contrario, normas tales como el decreto 269/993 establece que "quedan obligados a satisfacer personal e ilimitadamente los aciertos" A

5 Manual de Contratos TOMO II, Beatriz Venturini. 
su vez, ella establece que las obligaciones que pueda el Estado asumir al celebrar contratos de apuesta y de juego no son naturales, sino civiles.

Adicionalmente indica que: "a partir de la entrada en vigencia de la 17.250, no puede negarse que se trata de una actividad de consumo: el estado provee un servicio a través de un contrato Bilateral, oneroso y aleatorio, convirtiéndose en proveedor (art 3). El sujeto que juega contra la prestación de un servicio de entretenimiento y por lo tanto, es consumidor (art. 2)." A su vez, "esta Ley consagra, particularmente, la responsabilidad objetiva del proveedor cuando del vicio del producto del que se sirve para cumplir su prestación resulte un daño al consumidor (art. 34)".

De modo que la autora en ocasión del análisis de la sentencia de 261/004 del TAC 7º, concluye: "si se trata de obligaciones civiles, es de aplicación de la ley de relaciones de consumo por lo que la pretendida cláusula exoneratoria resulta nula y manteniendo toda su vigencia el art. 33 según el cual la única eximente es la causa extraña no imputable, no siendo tal el vicio o mal funcionamiento".

A su vez, entiendo que en este caso debe claramente diferenciarse cuando quien explota juegos de azar es el Estado o un privado autorizado por éste, o si en su defecto son particulares sin autorización alguna.

Esto se debe a que si tomamos en cuenta a los privados que cuentan con una concesión para operar casinos, se les exige que ingresen en un proceso licitatorio, que realicen una inversión de envergadura acompañado de un hotel 5 estrellas, tengan auditorías mensuales y minuciosas que controlen sus ingresos y el estricto cumplimiento del contrato de concesión.

Todo esto enmarcado en resoluciones de Presidencia y contratos suscriptos por el Poder Ejecutivo. Es dable afirmar, que en estas situaciones, a diferencia de aquellos que simplemente mandan a hacer una máquina para poner en un local no destinado a juegos de azar, deben encontrarse bajo un paraguas legal que lo proteja.

\section{C. ¿Existen los controles adecuados por parte del estado a los casinos?}

Para que existan controles adecuados con cada uno de los actores regulados, es necesario que existan autoridades competentes.

Para el caso de los casinos del Estado, la autoridad competente para la explotación y control de su actividad es la Dirección General de Casinos, una dependencia del Ministerio de Economía y Finanzas.

En el caso de los casinos municipales, la autoridad competente es la Dirección de Casinos Municipales.

En cuanto a los privados, eso se encuentra determinado en su respectivo contrato de concesión.

Para el caso de las licitaciones públicas, éstas son controladas por el Tribunal de Cuentas. Autoridad que únicamente puede hacer observaciones y comunicarlas a la junta o el Poder Legislativo, sin tener facultades para emitir sanciones al concesionario. 
Por su parte, tanto casinos privados como estatales, se encuentran regidos por la misma autoridad en las siguientes materias:

- Prevención de lavado de activos y financiamiento del terrorismo (SENACLAFT)

- Control y fiscalización del ingreso de menores (INAU).

- Control y fiscalización de ambientes libre de humo de tabaco (MSP).

- Control y fiscalización en derecho laboral (MTSS).

- Ley de defensa del consumidor.

- Control y fiscalización del Juego Online

Lo anterior es perfectamente entendible en un Estado de Derecho donde el Estado se reserva para si una actividad.

Por lo que las dudas aparecen frente a nuevos actores que han venido desarrollando una misma actividad que las que el Estado explota directamente (o a través de un privado debidamente autorizado), solo que al margen de todos los controles establecidos bajo el presente capítulo.

Estos actores lo hacen sin contar con autorización previa alguna, sin que se le practiquen auditorías ni controles de ningún tipo y sin dar las garantías ni respaldo necesario. Estos nuevos actores que se han extendido en el país en los últimos años, explotan una actividad de casino de forma abierta al margen de toda la normativa referida a lo largo del presente trabajo.

\section{C.1 Prevención de lavado de activos}

Con la emisión de la Ley 17.835 y su decreto reglamentario, 355/2010 se incluyó expresamente a los casinos como sujetos obligados en la prevención del lavado de activos.

Posteriormente a partir de la sanción de la ley 19.574 y su decreto reglamentario $379 / 18$, fue derogada la normativa indicada precedentemente, siendo ésta la que rige en la materia.

\section{C.1.A Ley 19754 Ley integral contra el lavado de activos}

Al respecto, establece como sujetos obligados no financieros en el artículo 13 a los siguientes:

(Sujetos obligados no financieros).- Con las mismas condiciones también estarán sujetos a la obligación establecida en el artículo anterior:

A) Los casinos.

B) Las inmobiliarias, promotores inmobiliarios, empresas constructoras y otros intermediarios en transacciones que involucren inmuebles, con excepción de los arrendamientos. 
C) Los abogados únicamente cuando actúen a nombre y por cuenta de sus clientes en las operaciones que a continuación se detallan y en ningún caso por cualquier tipo de asesoramiento que den a sus clientes:

1) Promesas, cesiones de promesas o compraventas de bienes inmuebles.

2) Administración del dinero, valores $u$ otros activos del cliente.

3) Administración de cuentas bancarias, de ahorro o valores.

4) Organización de aportes para la creación, operación o administración de sociedades.

5) Creación, operación o administración de personas jurídicas, fideicomisos u otros institutos jurídicos.

6) Promesas, cesiones de promesas o compraventa de establecimientos comerciales.

7) Actuación por cuenta de clientes en cualquier operación financiera o inmobiliaria.

8) Las actividades descriptas en el literal $H$ ) del presente artículo. Tratándose de venta de personas jurídicas, fideicomisos u otros institutos jurídicos, estarán obligados tanto cuando actúen a nombre propio como a nombre y por cuenta de un cliente.

D) Los escribanos o cualquier otra persona física o jurídica, cuando participen en la realización de las siguientes operaciones para sus clientes y en ningún caso por cualquier tipo de asesoramiento que les presten:

1) Promesas, cesiones de promesas o compraventas de bienes inmuebles.

2) Administración del dinero, valores u otros activos del cliente.

3) Administración de cuentas bancarias, de ahorro o valores.

4) Organización de aportes para la creación, operación o administración de sociedades.

5) Creación, operación o administración de personas jurídicas, fideicomisos u otros institutos jurídicos.

6) Promesas, cesiones de promesas o compraventa de establecimientos comerciales.

7) Actuación por cuenta de clientes en cualquier operación financiera o inmobiliaria.

8) Las actividades descriptas en el literal H) del presente artículo.

E) Los rematadores.

F) Las personas físicas o jurídicas dedicadas a la intermediación o mediación en operaciones de compraventa de antigüedades, obras de arte, y metales y piedras preciosas. 
G) Los explotadores y usuarios directos e indirectos de zonas francas, con respecto a los usos y actividades que determine la reglamentación.

H) Los proveedores de servicios societarios, fideicomisos y en general, cualquier persona física o jurídica cuando en forma habitual realicen transacciones para sus clientes sobre las siguientes actividades:

1) Constituir sociedades u otras personas jurídicas.

2) Integrar el directorio o ejercer funciones de dirección de una sociedad, socio de una asociación o funciones similares en relación con otras personas jurídicas o disponer que otra persona ejerza dichas funciones, en los términos que establezca la reglamentación.

3) Facilitar un domicilio social o sede a una sociedad, una asociación o cualquier otro instrumento o persona jurídica, en los términos que establezca la reglamentación.

4) Ejercer funciones de fiduciario en un fideicomiso o instrumento jurídico similar o disponer que otra persona ejerza dichas funciones.

5) Ejercer funciones de accionista nominal por cuenta de otra persona, exceptuando las sociedades que coticen en un mercado regulado y estén sujetas a requisitos de información conforme a derecho, o disponer que otra persona ejerza dichas funciones, en los términos que establezca la reglamentación.

6) Venta de personas jurídicas, fideicomisos u otros institutos jurídicos.

I) Las asociaciones civiles, fundaciones, partidos politicos, agrupaciones y en general, cualquier organización sin fines de lucro con o sin personería jurídica.

J) Los contadores públicos y otras personas físicas o jurídicas, que actúen en calidad de independientes y que participen en la realización de las siguientes operaciones o actividades para sus clientes y en ningún caso por cualquier tipo de asesoramiento que les presten:

1) Promesas, cesiones de promesas o compraventas de bienes inmuebles.

2) Administración del dinero, valores $u$ otros activos del cliente.

3) Administración de cuentas bancarias, de ahorro o valores.

4) Organización de aportes para la creación, operación o administración de sociedades.

5) Creación, operación o administración de personas jurídicas u otros institutos jurídicos.

6) Promesas, cesiones de promesas o compraventa de establecimientos comerciales.

7) Actuación por cuenta de clientes en cualquier operación financiera o inmobiliaria.

8) Las actividades descriptas en el literal $H$ ) del presente artículo. 
9) Confección de informes de revisión limitada de estados contables, en las condiciones que establezca la reglamentación.

10) Confección de informes de auditoría de estados contables.

Los sujetos obligados mencionados en los literales C), D) y J) del presente artículo, no estarán alcanzados por la obligación de reportar transacciones inusuales o sospechosas ni aún respecto de las operaciones especificadas en dichos numerales si la información que reciben de uno de sus clientes o a través de uno de sus clientes, se obtuvo para verificar el estatus legal de su cliente o en el marco del ejercicio del derecho de defensa en asuntos judiciales, administrativos, arbitrales o de mediación.

La información sobre operaciones inusuales o sospechosas deberá comunicarse a la Unidad de Información y Análisis Financiero del Banco Central del Uruguay. Esta Unidad, en coordinación con la Secretaría Nacional para la Lucha contra el Lavado de Activos y el Financiamiento del Terrorismo reglamentará la forma en que se realizará dicha comunicación.

Facúltase al Poder Ejecutivo a establecer, por vía reglamentaria, los requisitos que deberán cumplir estos sujetos obligados, para el registro de transacciones, el mantenimiento de los respectivos asientos y el desarrollo de la debida diligencia de los clientes o aportantes de fondos. Cuando los sujetos obligados participen en un organismo gremial que por el número de sus integrantes represente significativamente a la profesión u oficio de que se trate, el organismo de control en materia de lavado de activos y financiamiento del terrorismo podrá coordinar con dichas entidades la mejor manera de instrumentar el cumplimiento por parte de los agremiados o asociados de sus obligaciones en la materia. Si no existieran dichas entidades, el órgano de control podrá crear comisiones interinstitucionales cuya integración, competencia y funcionamiento serán establecidos por la reglamentación.

El incumplimiento de las obligaciones previstas para los sujetos obligados por el presente artículo determinará la aplicación de sanciones por parte de la Secretaría Nacional para la Lucha contra el Lavado de Activos y el Financiamiento del Terrorismo.

Dichas sanciones se aplicarán apreciando la entidad de la infracción y los antecedentes del infractor y consistirán en apercibimiento, observación, multa o suspensión del sujeto obligado cuando corresponda, en forma temporaria, o con previa autorización judicial, en forma definitiva.

Las suspensiones temporarias no podrán superar el límite de tres meses.

El monto de las multas se graduará entre un mínimo de 1.000 UI (mil unidades indexadas) y un máximo de 20.000.000 UI (veinte millones de unidades indexadas) según las circunstancias del caso, la conducta y el volumen de negocios habituales del infractor.

El Poder Ejecutivo establecerá los plazos, la forma y las condiciones en que se deberá dar cumplimiento a las obligaciones establecidas en este artículo.

La Secretaría Nacional para la Lucha contra el Lavado de Activos y el Financiamiento del Terrorismo podrá requerir a los sujetos obligados mencionados en este artículo, información pe- 
riódica de todo elemento que estime útil para el cumplimiento de sus funciones, los que estarán obligados a proporcionarla, bajo apercibimiento de que se apliquen las sanciones previstas en el presente artículo.

Una vez indicados quienes son los sujetos no financieros obligados, la Ley 19574 incluye otra serie de obligaciones de relevancia.

Así, a través de su artículo 14 establece la obligación de tener políticas realizar procedimientos de debida diligencia de todos sus clientes.

En línea de lo anterior en su artículo 15, da lineamientos sobre las medidas que deberán tomarse. En este sentido indica que se deberá: (i) Identificar y verificar la identidad de los clientes utilizando datos e información de fuentes independientes y confiables; (ii) Identificar al beneficiario final; (iii) Obtener información sobre el propósito de la relación comercial y la naturaleza de los negocios a desarrollar; y (iv) Realizar un seguimiento continuo y examinar las transacciones para asegurarse que sean consistentes con la obligación disponible.

Todas estas medidas, deben tener relación con el cliente en función del riesgo asignado. Dicho análisis del riesgo deberá constar por escrito, así aquellos clientes que involucren un riesgo reducido de lavado de activos y de financiamiento del terrorismo se le aplicarán medidas más simplificadas (arts. 17 y 18). Por su parte, aquellos clientes que impliquen un mayor riesgo, se les deberá implementar unas medidas de debida diligencia más intensificada.

La ley incluye como aquellos sujetos a los cuales deberá intensificarse la debida diligencia a los siguientes casos: (i) Clientes no residentes que vengan de países que no cumplan con estándares de prevención de lavado de activos; (ii) Aquellos en que la participación de la actividad no implica la presencia física de los mismos; (iii) Las personas políticamente expuestas; (iv) Personas jurídicas con acciones al portador; y (v) fideicomisos.

En nuestro caso particular, por tratarse de casinos donde está la persona jugando en el casino en ese momento, habrá que reparar en las políticamente expuestas.

La ley define a éstas en su artículo 20 como: "Se entiende por personas políticamente expuestas a aquellas que desempeñan o han desempeñado en los últimos cinco años funciones públicas de importancia en el país o en el extranjero, tales como: jefes de Estado o de Gobierno, politicos de jerarquí, funcionarios gubernamentales, judiciales, o militares de alta jerarquía, representantes y senadores del Poder Legislativo, dirigentes destacados de partidos políticos, directores y altos ejecutivos de empresas estatales y otras entidades públicas.

También se entiende como personas politicamente expuestas a aquellas personas que desempeñan o han desempeñado en los últimos cinco años una función de jerarquía en un organismo internacional, como ser: miembros de la alta gerencia, directores, subdirectores, miembros de la junta o funciones equivalentes". 
Por su parte, entiendo que las otras medidas aquí incluidas tales como Clientes no residentes que vengan de países que no cumplan con estándares de prevención de lavado de activos y aquellos en que la participación de la actividad no implica la presencia física de los mismos sería más de aplicación para aquellas modalidades de juego online.

Esta Ley continúa indicando otro tipo de obligaciones tales como: (i) conservación de registros, (ii) obligación de reserva; (iii) exención de responsabilidad; e (iv) inmovilización de fondos.

Estas cuatro obligaciones, ya se encontraban consagradas en la Ley 17835 y fueron vueltas a incluir en la Ley 19574.

\section{C.1.B. Decreto reglamentario 379/18}

Como consecuencia de la actualización de la normativa en prevención de lavado de activos referida precedentemente, Presidencia de la República a través de la Secretaría Nacional para la Lucha contra el Lavado de Activos y Financiamiento del Terrorismo (SENACLAFT) procedió a reglamentar la Ley 19.574.

Pero en este caso, a diferencia de lo ocurrido con el decreto 355/2010, este decreto fue la consecuencia de un trabajo mancomunado entre dicha Secretaría y cada uno de los sujetos obligados.

Así fue que en ocasión de reglamentar el capítulo III, casinos, la SENACLAFT se reunió con los mismos. Por lo que en dichos encuentros te trabajo, participaron delegados de Casinos del Estado, Casino Municipal Parque Hotel, Sofitel de Carrasco y Enjoy Punta del Este.

En dichos encuentros nunca participaron representantes de las máquinas tragamonedas clandestinas.

En este decreto en su artículo 22 establece un umbral mínimo a partir del cual se deberán realizar los procedimientos de debida diligencia. Aquí se mantiene el umbral fijado por el decreto 355/2010 de USD 3.000, pero flexibiliza el criterio utilizado a los efectos de determinar cuándo las operaciones múltiples son consideradas una sola operación.

Posteriormente indica que los sujetos obligados, deberán aplicar una clasificación de los riesgos, entre las categorías de riesgo bajo, medio y alto.

Aquí, todos los habilitados a desarrollar el juego de azar deben practicar lo siguiente:

A) debida diligencia simplificada, para lo cual deberán obtener los siguientes datos: (i) nombre completo; (ii) documento de identidad; (iii) domicilio; y (iv) fecha y lugar de nacimiento.

Adicionalmente, en el marco de esta debida diligencia simplificada debe determinarse si el cliente actúa a nombre propio o de un tercero, verificar las listas del consejo de seguridad de las naciones unidas y solicitar determinada información cuando se interac- 
túa con personas jurídicas (no sería el caso de casinos).

B) debida diligencia normal. Aquí se hace una diferenciación si se trata de personas físicas de jurídicas.

(I) Personas físicas: Los sujetos obligados deberán conseguir los siguientes datos: (i) nombre completo; (ii) documento de identidad; (iii) domicilio; (iv) fecha y lugar de nacimiento; (v) Profesión, oficio o actividad.

Adicionalmente, en el marco de esta debida diligencia debe determinarse si el cliente actúa a nombre propio o de un tercero; verificar las listas del consejo de seguridad de las naciones unidas; buscar antecedentes en base de datos; y obtener una declaración a los efectos de determinar si es o no persona políticamente expuesta.

(II) Personas jurídicas: información societaria, datos del representante y certificado de vigencia cuando sean sociedades extranjeras.

C) Debida diligencia intensificada. Cuando los casinos entiendan que esa operación específica con esos determinados clientes implique un mayor riesgo, adicionalmente a lo exigido para la debida diligencia normal, se deberá solicitar lo siguiente:

(i) volumen de ingresos y/o justificación razonable y/o justificación sobre el origen de los fondos manejados en la transacción;

(ii) estado civil de las personas y en caso de ser casados, datos del cónyuge;

(iii) obtener una declaración de regularidad fiscal;

(iv) una información específica para sociedades obligadas a registrarse frente al BCU según lo establecido por la Ley 18.930 y 19.484.

Por último, el decreto reglamentario regula específicamente las situaciones en que un cliente se niega a presentar determinada información así como también (piedra angular para la prevención del lavado) establece los criterios a través del cual un casino puede emitir una transferencia bancaria, un cheque o una certificación de ganancia.

\section{C.1.C. Conclusión}

A la luz de toda la normativa analizada, podemos vislumbrar todo un conjunto de obligaciones a las cuales deben cumplir los casinos. Estas obligaciones, ha sido de dificultosa implementación para algunos casinos, en especial del Estado.

Esto se debe a que una carga logísitca y de recursos enorme para lo cual varios de los casinos no se encontraban preparados. Sin perjuicio de lo anterior, deben cumplir.

Esto habla a las claras de que el Estado a través de la sanción de la Ley 19.574 y su decreto reglamentario enmarcó a los casinos habilitados a cumplir con toda la normativa relacionada a la prevención del lavado de activos. 
En ningún momento fueron incluidos los operadores ilegales de tragamonedas en dicha normativa ni en los encuentros de trabajo con la SENACLAFT.

Por lo que los operadores de máquinas ilegales de tragamonedas no solo lo hacen al margen de la ley al operar sin habilitación ni control de ningún tipo, sino que tampoco están aplicando ninguna de la normativa tendiente a prevenir el lavado de activos y financiamiento del terrorismo.

De modo que a mi entender, todo el esfuerzo del Estado a través del Poder Legislativo y Ejecutivo respectivamente, es abarcativo del juego legal únicamente. Por lo que esa ventana que se deja abierta, es justamente una que permite que los lavadores puedan obviar toda la reglamentación vigente a través del juego clandestino.

Como si esto no fuera suficiente, entiendo que el principal riesgo no está dado en los "clientes" de las máquinas legales clandestinas. Entiendo que el mayor riesgo de lavado, está dado en los propios operadores de las máquinas clandestinas.

Mientras los casinos que operan dentro del marco de la ley, están obligados a proporcionar la información requerida a las autoridades correspondientes y son minuciosamente auditados, los operadores de máquinas tragamonedas clandestinas lo hacen al margen de todo tipo de control.

Tanto es el control del estado, que en ocasión de la autorización al llamado a Licitación Pública No01/2019, el Ministerio de Turismo en conjunto con el Ministerio de Economía y Finanzas y el Presidente de la República emitieron la resolución el día 25 de noviembre de 2019 a través del cual también autorizaron el pliego de condiciones administrativas y anexos.

En dicho pliego de condiciones establece como condición necesaria y previa, la resolución de adjudicación por parte de la SENACLAFT. Para tal fin se adjunta un anexo, el cuarto, el cual debe ser presentado en una carpeta por separado con toda la información ahí contenida. ${ }^{6}$

Por lo que independientemente de toda la información requerida y previamente analizada, se entiende como una condición precedente, cumplir con el instructivo preparado por la Senaclaft, el cual requiere lo siguiente:

A) Nombre de la persona jurídica, número de RUT, nombre de fantasía, domicilio, teléfono y correo electrónico.

B) información particular de los socios, directores, gerente general, principales gerentes, administradores y beneficiarios finales.

C) Testimonio notarial del estatuto o contrato social, así como declaratoria inscripta en caso de proceder.

6 https://medios.presidencia.gub.uy/legal/2019/resoluciones/11/mintur_342.pdf 
D) Acreditar cadena de accionistas hasta llegar al beneficiario final.

E) Declaración jurada del beneficiario final;

F) Acreditación del origen de fondos a utilizar en el proyecto;

Esto sería a resumidas cuentas.

Y esta postura tiene todo el sentido. El Estado busca que este tipo de emprendimientos no sea utilizado como un mecanismo hábil de inversión y circulación de activos, utilizado para lavar y/o para financiar el terrorismo.

Por lo que visto y considerando que el Estado con acierto ha designado a quienes desarrollan el negocio de los juegos de azar como sujetos obligados y sometidos a un fuerte control, cuesta entender cómo están dejando fuera del control a aquellos que desarrollan el mismo negocio en la clandestinidad, pero que operan a la vista de todos.

Por lo que entiendo, que aquellos que explotan el negocio de las máquinas tragamonedas clandestinas a plena luz del día y a lo largo y ancho del país, disponen de un vehículo hábil con la que pueden utilizar largas sumas de efectivo con amplia disponibilidad horaria los siete días de la semana para proceder al ocultamiento y transformación de dinero proveniente de actividades ilícitas.

Pero no solo pueden lavar dinero proveniente de actividad ilícitas a través de falsas ganancias, sino que con dinero proveniente de actividades ilícitas, están invirtiendo en la explotación de una actividad prohibida por Ley.

\section{C.2. Ingreso de niños y adolescentes a espacios donde se realicen juegos de azar}

El INAU en el marco de lo establecido en el artículo 186 del código de la niñez y la adolescencia, Ley 17.823, establece expresamente la prohibición de las personas menores de 18 años a concurrir los casinos.

"Prohíbese la concurrencia de personas menores de dieciocho años a casinos, prostíbulos y similares, whiskerías y clubes nocturnos, independientemente de su denominación.

El Instituto del Niño y Adolescente del Uruguay (INAU) reglamentará a los efectos pertinentes la concurrencia de adolescentes a locales de baile, espectáculos públicos de cualquier naturale$z a$, hoteles de alta rotatividad y afines.

Corresponde asimismo al Instituto del Niño y Adolescente del Uruguay (INAU) regular la asistencia de niños y adolescentes a espectáculos públicos de cualquier naturaleza."

Este artículo se complementa con el art 188 el cual establece la fiscalización y correspondientes sanciones por parte del INAU, tal como se cita a continuación:

“1) La fiscalización de lo establecido en los artículos 181 a 187 de este Código, será facultad del Instituto del Niño y el Adolescente del Uruguay. 
2) Las empresas o los particulares que no cumplan con las obligaciones impuestas en los artículos 181 a 187 de este Código, serán sancionados con una multa de entre 50 UR (cincuenta unidades reajustables) y 200 UR (doscientas unidades reajustables), según los casos. En los casos de reincidencia, podrán hasta duplicarse los referidos montos. Las multas serán aplicadas y recaudadas por el Instituto del Niño y Adolescente del Uruguay.

El niño o adolescente encontrado en situación de riesgo será conducido y entregado por parte del Juez a los padres, tutor o encargado. El Juez advertirá a éstos personalmente y bajo su más seria responsabilidad de la situación. Si éstos han incumplido alguno de los deberes establecidos en el artículo 16 de este Código, el niño o adolescente será entregado al Instituto del Niño y Adolescente del Uruguay (INAU).

El Instituto del Niño y Adolescente del Uruguay (INAU) podrá solicitar al Juez competente la clausura, por veinticuatro horas a diez días, del establecimiento en infracción."

A tales efectos, en todos los casinos autorizados existe una planilla anual de control, proporcionada por el Departamento de Espectáculos Públicos del INAU la cual debe permanecer en un lugar visible en el local y ser entregada a los inspectores del INAU en ocasión de cada visita de los mismos.

Estos inspectores, en el marco de cada visita que realizan a cada casino, firman y sellan una vez realizado el control.

Por lo que a la luz de lo establecido precedentemente, podemos enmarcar otra gran diferencia entre los casinos y los operadores de máquinas tragamonedas clandestinas. Los últimos, en el marco de su comparecencia frente a la Comisión de Hacienda del Parlamento el día 04 de mayo de 2016, afirmaban que estaban dándole cumplimiento a los requisitos de protección del menor y el adolescente al colocar un cartel en las máquinas indicando que su utilización es para mayores de 18 años.

Cuesta creer la dualidad de criterios que existe entre un operador y otro.

Mientras a los casinos legales y habilitados por ley, les resulta aplicable el código de la Niñez y la Adolescencia y tienen vistas fiscalizadoras constantes, aquellos que operan el margen de la ley entienden que protegen al menor y al adolescente únicamente colocando un cartel con la indicación que dichas máquinas son para mayores de 18 años de edad.

\section{C.3. Controles en el marco de la normativa de humo}

En el marco de la Ley 18256 y su decreto reglamentario (284/08), se dispusieron medidas tendientes al control del tabaco a fin de reducir de manera continua y sustancial la prevalencia de su consumo y exposición al humo del mismo.

En línea de lo anterior, se establece una serie de prohibiciones, en especial la prohibición de fumar en espacios cerrados, así como en espacios abiertos que no estén de conformidad con los requisitos edilicios exigidos por la normativa. En especial lo referente a que sean en espacios abiertos sin techo de ningún tipo. 
En línea de lo anterior, todos los casinos tuvieron que adecuarse a la misma de forma inmediata y son objeto de control por parte del Ministerio de Salud Pública de forma constante.

\section{C.4 Conductas problemáticas con el juego y programas de juego responsable}

\section{C.4.A. Conductas problemáticas del Juego}

Como lo estableció Carlos Delpiazzo7, la palabra "casino" proviene del italiano "casa de campo", se designa en sentido amplio al lugar de reunión y diversión, originariamente en los balnearios.

Por su parte, los autores Emilia Palumberri y Giusseppe Manino ${ }^{8}$, analizaron la evolución de los juegos de azar, e indican que estos comenzaron en el 3000-4000 a. C. Esto fue cuando en la sociedad egipcia se practicaba el juego, como testimonia el hallazgo de imágenes de dados y de jugadores. El término "azar" deriva de la palabra francesa "hasard", que a su vez deriva del árabe "az-zahr", un antiguo juego oriental de dados.

Por lo que los juegos de azar claramente tienen una finalidad de recreación y diversión. No obstante, tal como lo estableció José Bermejo Vera, sin un correcto marco legal y sin las debidas protecciones a los usuarios, puede traer aparejado posibles daños o consecuencias no deseadas a éstos.

Lo anterior refiere a aquellas personas que presentan una conducta de juego problemática o incluso adicciones a los juegos de azar (ludopatía).

La Real Academia Española define la ludopatía como un "adicción patológica a los juegos electrónicos o de azar", mientras que por adicción entiende que: "dependencia de sustancias o actividades nocivas para la salud o el equilibrio psíquico" o "afición extrema a algo o alguien".

Los autores Emilia Palumberri y Giusseppe Manino 9 indicaron que el concepto de adicción al juego de azar o "gambling" es reconocido oficialmente por el American Psychiatric Association, a partir de la III edición del Manual Estadístico-Diagnostico del 1980, como una nueva categoría diagnostica y así fue incorporado por la Organización Mundial para la Salud. Esta última reconoce al juego compulsivo también a partir de 1980 como una enfermedad emocional donde la persona desarrolla de forma crónica y progresiva la incapacidad de resistir el impulso de jugar.

De modo que recalcamos una vez más, la importancia que los juegos de azar, sean desarrollados con los debidos controles y dentro de un marco legal regulado dando mayores garantías a todos los usuarios.

$7 \quad$ Carlos E Delpiazzo DERECHO ADMINISTRATIVO ESPECIAL Volumen 2. Pag. 519

8 Emilia Palumberri y Giusseppe Manino Ludopatia, un estudio comparativo entre realizado en Italia y España Humanismo y trabajo social, Vol 7, 2008pp 155-196 Universidad de Leon, España

9 Emilia Palumberri y Giusseppe Manino Ludopatia, un estudio comparativo entre realizado en Italia y España Humanismo y trabajo social, Vol 7, 2008pp 155-196 Universidad de Leon, España 


\section{C.4.B. Programas de Juego Responsable}

Todos los casinos que operan bajo el régimen legal vigente en Uruguay, han ido desarrollando e implementando programas para un juego responsable.

\section{C.4. B.i Programa de un casino privado (Enjoy Punta del Este)}

Así, uno de los casinos privados que opera en Punta del Este, desarrollo un programa denominado "Jugados Por Ti". El mismo surge como consecuencia de su compromiso con el cliente y el entretenimiento responsable.

Por lo que luego de varias participaciones en distintos seminarios internacionales desarrollados en Las Vegas, esta compañía, ENJOY, rescata el modelo PETER del National Council on Problem Gambling. El nombre de este modelo obedece a las siguientes siglas: (i) Prevention (prevención); (ii) Education (educación); (iii) Treatment (tratamiento); (iv) Enforcement (cumplimiento de la notmativa vigente); y (v) Research (investigación). Éstas, simbolizan los 5 ejes de este modelo para abordar la problemática de la ludopatía.

Así fue que la compañía Enjoy desarrollo el programa Jugados por Ti desde el año 2008 a esta parte. De esta forma, esta iniciativa pionera en el continente impulsa políticas y prácticas responsables para promover el juego responsable y el cuidado de los clientes.

El mismo consiste en otorgarle a familiares y clientes distintos tipos de herramientas, para que puedan desarrollar un juego responsable. Así es que tanto al cliente como a su familia un servicio de orientación telefónica donde se le puede dar al cliente apoyo psicológico, legal o financiero.

Este apoyo puede ser a través del suministro de un servicio de asistencia telefónica el cual es gratuito, confidencial y voluntario.

Aquí tanto el cliente como sus familiares pueden ser asistidos por profesionales expertos en el abordaje de conductas adictivas.

A su vez, aquellos clientes que vean que su juego puede estar siendo problemático, podrán apoyarse en consejeros de juego responsable quienes pueden darle el apoyo necesario así como suministrarle y asistirlo en opciones y alternativas para tratar su juego problemático. Una de estas alternativas es la posibilidad de autoexcluirse a las salas de juego. Ésta si bien es un fuerte apoyo en la recuperación de los clientes con problemas en su forma de jugar, ya que facilita la modificación de los hábitos de juego y refuerza la reposición del autocontrol, por sí sola no logrará que una persona resuelva su relación problemática con el juego. Para esto último existen profesionales especializados.

\section{C.4.B.ii. Programas de Casinos del Estado}

Siguiendo la misma línea del este casino privado, Casinos del Estado ha implementado el Programa de Juego Responsable.

Aquí dicha entidad estatal firmó un convenio con la Facultad de Medicina de la Uni- 
versidad de la República para la prevención y tratamiento de la Ludopatía.

También incluyeron un 0800 con asistencia telefónica gratuita así como también da asesoramiento en sobre distintos centros de ayuda al juego problemático

\section{C.4.C Conclusión.}

Habiendo analizado brevemente los riesgos asociados al juego, por un lado podemos encontrar a los actores autorizados que buscan lograr clientes saludables, tanto en lo individual, brindando una debida asistencia al afectado; como en el ámbito familiar, haciendo una propuesta contemplando el apoyo a los miembros de la familia del jugador problemático con información y asistencia desde un centro específico, serio y científico, posicionándose con responsabilidad para dar respuestas y soluciones.

Cuesta creer como en ese contexto los operadores pueden dar algún tipo da garantías. Máxime, cuando aún sus productos carecen de auditoria de tipo alguno y únicamente encuadran un acuerdo entre el dueño del local y el de la máquina.

\section{Máquinas tragamonedas clandestinas.}

Siguiendo la línea de lo establecido precedentemente, no puede dejar de notarse la notoria mayor presencia de máquinas ilegales tragamonedas en distintos locales comerciales del país.

\section{D.1. Análisis de la sentencia del TCA Nº 381 del 30 de septiembre de 2014}

Al respecto, existe un antecedente jurisprudencial al respecto es el de la sentencia del TCA No 381 del 30 de septiembre de 2014.

Ésta refiere a la anulación de la Orden de Servicio No328280 emitida por el Servicio Central de Inspección General de la Intendencia de Montevideo del 29 de julio de 2011 a través de la cual se resolvió "Intimar el retiro de las máquinas tragamonedas con un plazo de 48 horas bajo apercibimiento de sanción en caso de omisión por ART D 2863, Lit B del Volúmen XIII del Digesto Municipal y Resolución 3522/06 del 15/09/2010 del Intendente de Montevideo".

Los fundamentos de fondo de la sentencia refieren a:

A) que la explotación de las maquinitas electrónicas objeto de estos obrados constituyen una actividad lícita, que no ha sido monopolizado por el Estado. Se trata de una actividad que se halla dentro del ámbito de la libertad de los particulares (artículos 7, 10, 36, 85 num $17^{\circ}$ de la Constitución. Adicionalmente el TCA estableció "ninguna disposición con valor y fuerza de Ley - única que podría hacerlo - ha prohibido esta actividad, ni la ha quitado del ámbito de la libertad, para consagrar un monopolio a favor del Estado.

B) que la intimación se fundó en ART D 2863, Lit B del Volúmen XIII del Digesto Municipal que refiere a los locales destinados a entretenimientos electrónicos. Dicha normativa expresamente prohíbe en esos locales "efectuar apuestas o dar premios de dinero y/o instalar máquinas de azar". 
Como las máquinas tragamonedas que originaron estos obrados estaban en un bar, no le es aplicable la normativa prevista para los locales destinados a entretenimientos electrónicos.

C) "que los gobiernos Departamentales carecen de potestad para imponer limitaciones a los derechos fundamentales, como lo es la libertad de comercio (art. 36 de la Constitución de la República). La limitación de esos derechos requiere de la existencia del dictado de una ley en sentido formal y material.

D) Que por lo expuesto, sostiene que el artículo del Digesto Municipal que se aplicó para fundar la infracción resulta, por un lado inaplicable a la situación de la actora, porque no se halla bajo su supuesto. $Y$, aun si lo estuviera, carecería de valor y fuerza para limitar el desarrollo de una actividad lícita porque, conforme a la Constitución, solamente una ley nacional puede quitar una actividad del ámbito de la libertad.

E) que el acto impugnado también se funda en la resolución de la Intendencia Municipal De Montevideo $N^{o} 3522 / 2006$, por la que se resuelve "comunicar a los establecimientos comerciales del Departamento que la normativa vigente no permite la instalación de máquinas tragamonedas en comercios u otros establecimientos de acceso público, cuya habilitación municipal fue concedida con otros destinos". Esta resolución también establece que: "de comprobarse la existencia de las mismas se intimará su retiro y se comunicará tal circunstancia a la Dirección Nacional de Casinos. En caso de incumplimiento de la intimación podrá disponer de la clausura temporaria o definitiva del establecimiento.

Tal como lo establece Augusto Durán Martínez en su muy completo artículo ${ }^{10}$, la sentencia entiende que esa resolución es ilegítima porque sin Ley en sentido orgánico formal, no puede disponerse tal prohibición.

Llama la atención esta conclusión a la cual llega el TCA. A mi entender, el TCA dictó la sentencia sin tomar en consideración una Ley que expresamente regula el tema, Ley 1595. Tampoco lo hizo tomando en consideración ninguna de la normativa posterior ya citada.

Adicionalmente, dentro de su profundo y detallado informe, Augusto Durán Martínez también fundamenta otros aspectos a destacar. Entre ellos, menciona que la actividad de casino es de naturaleza privada, pero monopolizada a favor del Estado. En esta línea, el establece que: "Es obvio que la actividad de casinos no es inherente al Estado, por lo que no es un cometido esencial del Estado. Tampoco se puede decir que el Estado asuma esa actividad para satisfacer necesidades colectivas impostergables, por lo que no es un servicio público. No reúne características de los servicios sociales y admite ser monopolizada, por lo que no configura un servicio social. No queda, así, otra alternativa, que considerarla una actividad privada a cargo del Estado. Una actividad que el Estado en determinado momento consideró, por razones de interés general, necesario asumir, y hacerlo en régimen de monopolio".

Adicionalmente, también estableció que: "desde otro punto de vista, las actividades pueden ser lícitas o ilícitas. Son ilícitas las prohibidas por la Constitución o la Ley o por otro acto jurídico que cuente con la debida habilitación constitucional o legal.

10 Estudios de Derecho Administrativo - Nº13 - Año 2016. Máquinas tragamonedas, Augusto Duran Martínez. 
Cuando la ilicitud reviste de particular gravedad, se le asigna naturaleza penal. Pero no toda ilicitud es penal. Así, fumar en un salón de clase de una universidad configura una conducta ilícita, no penal, ya que no es susceptible de una sanción penal, pero si produce consecuencias jurídicas que pueden llegar a sanciones civiles o administrativas."

Siguiendo esa línea, concluye: "la explotación de slots por tratarse de un juego de azar, es en principio ilícita. No es de actividad libre, por lo que no está regida por el derecho de la competencia. Las máquinas tragamonedas solo serán explotadas lícitamente por casinos administrados directamente por el Estado, tanto en forma tradicional como en el mal llamado sistema mixto, o por casinos privados que hayan obtenido la correspondiente concesión o autorización, en el estricto marco de las mismas".

\section{D.2. Análisis de la comparecencia de la Asociación Nacional de Juegos del Entrete- nimiento (ANJE) en la Comisión de Hacienda del Parlamento}

Como si del análisis de esta sentencia del TCA más lo expresado dentro de este trabajo no fuera suficiente, también se procederá a desmenuzar la comparecencia de la Asociación Nacional de Juegos del Entretenimiento (ANJE) a la Comisión de Hacienda del Parlamento el día 04 de mayo de 2016, en ocasión de la discusión de un proyecto de Ley que se estaba discutiendo por aquel entonces relativo a un proyecto de Ley tendiente a darle un marco legal al juego.

Este proyecto de Ley fue enviado por el Ministerio de Economía y Finanzas al Parlamento el 20 de marzo de 2014 y tenía como objetivo la reorganización institucional de los juegos de azar, separando las funciones de regulación y control, de la actividad directa de explotación de los mismos.

Básicamente el proyecto de ley tendía a regular dos aspectos: 1) otorgar al Estado un monopolio del desarrollo de la actividad lúdica, permitiendo el otorgamiento de autorizaciones, licencias, permisos y concesiones a terceros (Art. 1: Ratifícase que el Estado ejerce el monopolio de todo tipo de juego, apuesta, suerte, rifas y similares en los que intervenga el público o se encuentre por su propia naturaleza dirigido o abierto al público apostador". A su vez este mismo proyecto establecía: “En general queda prohibida la gestión, explotación, financiación y práctica de todos los juegos y apuestas que no cuenten con las autorizaciones, permisos, licencias o las concesiones otorgadas por los órganos estatales competentes, así como aquellos que - contando con la autorización, permiso, licencia o concesión sean realizados en forma, lugar o por personas diferentes de las especificadas".

En la versión taquigráfica del día 04 de mayo de 2016, la citada asociación manifiesta como argumentos de legalidad de su operativa, los siguientes:

- Realizan los aportes al BPS por los empleados de sus comercios y a DGI por la compra y venta de las máquinas tragamonedas.

- Son empresas pequeñas que deben competir contra grandes capitales, y su negocio consiste básicamente en la importación de un software, para que luego un carpintero local arme una consola. 
- Su modelo de negocios consiste en repartir el 50\% de la recaudación entre el dueño del local y el dueño de la máquina. No surge de estas declaraciones si tienen algún tipo de auditoría. Lo que sí surge, que en opinión de la ANJE, el apego a lo legal estaría dado por la celebración de un contrato de arrendamiento de la máquina ya que de esa forma se pueden identificar a las partes.

- Entienden que están dando cumplimiento a los requisitos de protección del menor y el adolescente al colocar un cartel en las máquinas indicando que son para mayores de 18 años.

- Establecen que es una actividad no regulada que se enmarca dentro de lo que es la libertad del comercio.

- A su vez dicen que se encuentra enmarcado dentro del derecho del trabajo de los hombres. Por tal motivo ese proyecto de Ley, debería incluir a la actividad de estas máquinas tragamonedas.

- Indican que se tratan de derechos adquiridos por la ANJE, por lo cual no se debería modificar la situación de ésta so pena de responsabilidad del Estado.

- Establecen que la Ley 1595 no está vigente por ser del Siglo XIX.

- Por un tema de inclusión social, la ANJE debe ser considerada como un actor formal más.

- Establecen que dejaría en una franja de vulnerabilidad a los pequeños comercios, que en caso de que no se las legitime, van a tener que trabajar en negro.

- Hablan de la existencia de dos modalidades: una profesional (casinos) y otra semi amateur (ANJE) por no disponer de la misma tecnología. Siendo este, un argumento al entender de la ANJE que les permita ser considerado como un actor legal habilitado a desarrollar juegos de azar.

- Por último, establecen que el proyecto de Ley es inmoral porque se tipifica a las máquinas tragamonedas como ilegales. El ser un delito, estaría afectando moralmente a los explotadores por considerarlos explotadores de una actividad delictiva.

A fin de cuentas, a partir de esta propia declaración de la ANJE queda en evidencia que no tienen licencia de ningún tipo para operar.

Si esto no fuera suficiente, carecen de cualquier tipo de auditoría y control o protección a través de CCTV para los usuarios.

Adicionalmente carecen de cualquier tipo de protocolo o políticas relacionadas con la prevención de lavado de activos o relativas a la protección de menores de 18 años de edad, así como tampoco se enmarcan en ningún programa de juego responsable.

Por lo que podemos afirmar que no solo explotan una actividad prohibida por ley, sino que también lo hacen incumpliendo toda la normativa y mejores prácticas asociadas.

Todo esto sin consecuencias de ningún tipo. 


\section{E. Proyecto de actualización de la normativa en Uruguay}

Como mencionado precedentemente, durante el año 2014 el Ministerio de Economía y Finanzas envió al Parlamento un proyecto de ley que tenía como objetivo la reorganización institucional de los juegos de azar.

Este ambicioso proyecto, en resumidas cuentas, trataba los siguientes temas:

i. Ratificación del monopolio de los juegos de azar por parte del Estado;

ii. Control del juego en todas sus modalidades;

iii. Creación de un nuevo ente regulador para todos los actores;

iv. Creación de un ente estatal explotador de los juegos de azar en sustitución de la actual Dirección General de Casinos;

v. Tipificación de un Delito para quienes exploten o participen en juegos de azar no autorizados.

Entiendo que este proyecto de Ley independientemente de sus defectos y virtudes recogía una necesidad clara necesidad de centralizar y regular los juegos de azar en una única norma.

Este proyecto de ley comenzaba diciendo en su artículo primero: "ratifíquese que el Estado ejerce el monopolio de todo tipo de juego, apuesta, suerte, rifas y similares en los que intervenga el público o se encuentre por su propia naturaleza dirigido o abierto al apostador".

Entiendo que una definición de este tipo es de suma importancia en el marco legal actual. A través de la presente ratificación se crea una norma en la cual impone y reconoce a texto expreso el monopolio a favor del Estado de todas las formas de juego de azar. Por lo que de haberse aprobado este proyecto de Ley se incluiría en una sola norma amplia y abstracta la inclusión de todos los sectores de juego.

Seguidamente el proyecto de Ley incluía lo siguiente: "En general queda prohibida la gestión, explotación, financiación y práctica de todos los juegos y apuestas que no cuenten con las autorizaciones, permisos, licencias o las concesiones otorgadas por los órganos estatales competentes, así como aquellos que - contando con la autorización o permiso, licencia o concesión sean realizados en forma, lugar o por personas diferentes de las especificadas".

Por lo que a través del inciso final del artículo segundo este proyecto de ley buscaba ratificar el sistema prohibitivo.

A su vez, el proyecto de ley establecía un alcance amplísimo de lo que se pretendía regular a través del mismo. Esto lo realizaba a través de la definición de "juegos de azar" consagrada en su artículo tercero y del listado enunciativo que realiza. A su vez en el artículo 5 mencionaba todas las actividades que quedaban incluidas dentro de esa definición, a saber: "1. Explotación de casinos en su modalidad tradicional así como los juegos 
de mesa y electrónicos que los mismos desarrollen. 2. Explotación de las máquinas tragamonedas, sean instaladas en casinos o locales dirigidos a tal fin. 3. Actividades hípicas cualquiera sea el régimen de sus apuestas. 4. Loterías y quinielas en sus modalidades y juegos derivados, así como juegos deportivos o informáticos, por internet, televisión interactiva, telefonía o, en general, ejecutados a distancia o por medios telemáticos de cualquier tipo o cualquier modalidad existente o a crearse en el futuro".

Por lo que dos de las grandes incorporaciones que de este artículo 5. Serían aquellos incluidos en los numerales 2 y 5 . A través del primero, dejaría entrever la posibilidad de autorizar las máquinas tragamonedas en lugares diferentes a una sala de casino habilitada, siempre y cuando cuenten con la autorización correspondiente.

Por su parte, el numeral 5 de dicho artículo establece que la posibilidad de regular los juegos de azar a través de medios electrónicos o informáticos en cualquier modalidad existente o a crearse en el futuro.

Entiendo que el proyecto de ley tendría que haber seguido la misma línea que para los casinos presenciales, por lo que hubiese sido preferible contemplar también la posibilidad de que este tipo de explotación de los juegos de azar sea realizado por los casinos privados.

Por su parte, la regulación de todas las formas de azar antedicha iba a ser controlada por un nuevo organismo a ser creado. Así es que dicho proyecto de ley a través de su artículo 10 creaba la Dirección Nacional de Loterías y Quinielas. Este organismo tenía como principal atribución ejercer en nombre del Estado el contralor de todo tipo de juego apuesta, suerte, rifas y similares en los que intervenga público o se encuentre por su propia naturaleza dirigido o abierto al público apostador.

Este nuevo organismo de contralor tendría no solo la responsabilidad y facultad de ser quien expida todas las autorizaciones, permisos, licencias o concesiones, sino que a su vez sería quien se encargue de la regulación del juego y las apuestas en todas sus modalidades de los casinos de gestión privada (...).

Por otro lado, por oposición al ente regulador referido precedentemente, el proyecto de Ley buscaba crear la Administración Nacional de Casinos y juegos de apuestas del Estado con la finalidad de que sea este servicio descentralizado comercial, el que explote la actividad de casinos y de apuestas. Por lo que se vislumbraría que esta nueva administración de casinos iba a ser creada para sustituir a la actual Dirección General de Casinos.

Por último, un punto destacable de este proyecto de ley, fue la tipificación de un nuevo delito penal. El Proyecto, en su artículo 36, establece que "el que en lugares públicos o accesibles al público, en contravención a las normas y reglamentos aplicables tuviere, explotare o facilitare juegos de azar, será castigado con tres meses de prisión a tres años de penitenciaría. El que en las mismas circunstancias tomare participación en juegos de azar será castigado con multa de 2500 a 25000 Unidades indexadas o prisión equivalente. 


\section{F. Juego online}

Originariamente, las regulaciones en torno a los juegos de azar giraban en torno el juego presencial en casinos. Esto se ha vuelto insuficiente con el surgimiento de formatos digitales que permiten a clientes poder jugar de forma remota sin importar las fronteras.

La regulación del juego on line varía mucho de país en país con un espectro que va de aquellos donde el juego esta explícitamente prohibido, ha desarrollado de forma monopólica por el estado, hasta aquellos donde el juego está totalmente abierto a operadores privados.

También existen países donde no han regulado los juegos de azar, por lo que aquí las interrogantes sobre su explotación o si es prohibido son mayores.

\section{F.1. Uruguay}

Tal como ya ha sido indicado previamente en el presente trabajo, con la aprobación de la Ley de Rendición de Cuentas del año 2017, Ley 19.535, establecieron la ilegalidad de esta modalidad de los juegos de azar.

Por su parte, a través del decreto reglamentario 366/017 encomendó a la Dirección Nacional de loterías y quinielas el relevamiento de los sitios web que realicen este tipo de explotación y su bloqueo.

Esta facultad otorgada a la Dirección Nacional de Loterías y Quinielas ha sido rígidamente adoptada por dicho organismo que ha fiscalizado y procedido al bloqueo de sitios web de forma exhaustiva en los últimos años.

Por último, también como fue analizado precedentemente, el proyecto de ley tendiente a regularizar todos los juegos de azar, también trató este tema buscando regular los juegos de azar a través de medios electrónicos o informáticos en cualquier modalidad existente o a crearse en el futuro. En ese proyecto de ley, no se buscó contemplar que este tipo de explotación sea realizada por los privados.

\section{F.2. Regulación del Juego Online en el extranjero}

Para el juego online, el espectro de regulación es muy amplio. En esta línea existen países cuya regulación lo prohíbe expresamente y otros donde esta práctica se encuentra totalmente aceptada y regulada. Por su parte, en una gran cantidad de países donde no se ha legislado en torno al juego online, por lo que su regulación es un tanto ambigua al no poder determinarse con claridad si está prohibido o permitido.

En esta línea, según un informe de Edinson Investment Research ${ }^{11}$, en Europa se encuentra desarrollado el 54\% (cincuenta y cuatro por ciento) del juego online. Adicionalmente, según este mismo informe, al 2018 el juego online involucraba el 15\% de todo el juego de azar.

11 Online gaming sector. Diversification and scale for online success. Julio 2019. https://www.edisongroup.com/ wp-content/uploads/2019/07/GamingSectorReport2019.pdf 
Tal como se desarrollará a continuación, el Reino Unido es el país con mayor regulación de Europa. Otros países que también se encuentran regulados son España e Italia.

\section{F.2.A Reino Unido ${ }^{12}$}

El Reino Unido es el país más "maduro" en cuanto a regulación, donde su mercado está ampliamente regulado el cual tiene al 2018, los mayores ingresos por juego online ascendiendo a 5.6 billones de libras por año. Estos ingresos se dividen entre apuestas deportivas y juegos de azar on line.

En gran medida, producto de la regulación sumamente permisiva, tuvo un crecimiento enorme en los últimos 5 años. Este crecimiento se ha visto disminuido producto de una mayor regulación que incluyó medidas de responsabilidad social empresarial, mayores restricciones a la publicidad, confirmación de identidad, medidas de prevención de lavado de activos.

Adicionalmente a estas medidas, el juego online ha sufrido una mayor carga tributaria.

A su vez resultado de esta ampliación y mayor rigidez en la normativa y de la mayor complejidad en tecnologías y su correspondiente aumento de costos, ha dado lugar a mayores barreras de entrada para nuevos operadores del mercado online.

\section{F.2.B. Italia ${ }^{13}$}

Italia es el segundo país en Europa entorno a regulación del juego online.

Según estudios, si bien este es un país con una buena proyección de penetración y expansión de mercado, la fuerte regulación en los últimos años ha dado lugar a que no se dé la expansión del juego online que se proyectaba.

En términos impositivos, desde enero 2019 se ha incrementado la carga impositiva de 22 a 24 por ciento en apuestas deportivas y de 20 a 25 por ciento en juego online.

\section{F.2.C Alemania ${ }^{14}$}

Alemania es uno de esos países cuyo régimen legal en torno al juego no está del todo claro, en especial en torno al juego online donde a la fecha se encuentra bajo discusión entre los diferentes estados alemanes si es una actividad permitida o no. Se entiende que está prohibido, con excepción de aquellos proveedores que ya tenían una licencia aprobada, en cuyo caso tienen una autorización provisoria.

A su vez, en este país al no haber una norma expresa que lo prohíba, las compañías utilizan licencias en otros países, como por ejemplo Malta. En Alemania es común que las empresas desarrollen el juego online según la licencia obtenida en Malta. Por lo que

12 https://www.edisongroup.com/wp-content/uploads/2019/07/GamingSectorReport2019.pdf

13 https://www.edisongroup.com/wp-content/uploads/2019/07/GamingSectorReport2019.pdf

14 https://www.edisongroup.com/wp-content/uploads/2019/07/GamingSectorReport2019.pdf 
de acuerdo a lo establecido por la normativa de la Unión Europea, estas licencias son permitidas en todos los países como consecuencia de la libertad de movimiento en la Unión Europea.

\section{F.2.D Estados Unidos ${ }^{15}$}

En el año 2018 se aprobó la PASPA, por sus siglas en inglés (Professional and Amateur Sports Protection Act). Esta fue una ley federal, la cual la Suprema Corte estadounidense determinó que cada estado de dicho país, determine si autoriza y regula la apuesta deportiva.

Al finalizar el año 2018, ocho estados habían regulado las apuestas deportivas, a saber: Nevada, Delaware. New Jersey, Mississippi, West Virginia, New Mexico, Rhode Island y Pennsylvania.

En cuanto al juego online, varios estados han anunciado un cambio en la regulación incluyendo la forma de casino online dentro de la misma. Al 2019, en Nevada y New Jersey, las apuestas online estaban $100 \%$ operativas. Adicionalmente, otros varios estados estaban trabajando en su regulación. En cuanto a los casinos online, estos están 100\% operativos en New Jersey, Delaware y Nevada (solo poker).

La carga impositiva varía en cada estado, oscilando de 8,5 a 34\% dependiendo del estado.

\section{F.2.E España ${ }^{16}$}

Las primeras licencias online fueron otorgadas en junio de 2012. Los operadores deben tener una licencia general y una licencia específica para cada actividad emitida por la Comisión Nacional de Juego.

En junio de 2015, diez nuevas licencias fueron otorgadas.

Durante el 2018 autoridad del juego en España (DGOJ) ha abierto su tercer llamado oficial a licitación. Aquellos operadores que aplicaron para licencias online, se les han otorgado licencias por un año.

Como consecuencia de la pandemia COVID-19, el gobierno español introdujo una serie de limitaciones mientras durara la cuarentena en cuanto a la publicidad y a la oferta de bonos

\section{F.2.F Colombia}

Con fecha 24 de mayo de 2016, se aprobó el reglamento de juego de suerte y azar de la modalidad tipo juegos operados por internet.

Por lo que a través de la misma se regula todos los requisitos necesarios a los efectos de desarrollar los juegos de suerte y azar por internet.

15 https://www.edisongroup.com/wp-content/uploads/2019/07/GamingSectorReport2019.pdf

16 https://www.igamingbusiness.com/analysis/wiggin-european-regulation-roundup-may-2020 
Así, a través de su artículo primero, establece que podrán operar los juegos de suerte y azar por internet las personas jurídicas que suscriban el correspondiente contrato de concesión con el Estado.

Este reglamento tiene la particularidad que el jugador debe estar domiciliado en Colombia. A su vez debe tener una cuenta abierta en una entidad financiera en Colombia.

\section{F.2.G Argentina}

Con fecha 20 de febrero de 2020, el gobierno de la ciudad de Buenos Aires, aprueba la convocatoria para el otorgamiento de permisos de agencias de juego en línea.

A resumidas cuentas, establece que podrán ser titulares de Agencias de Juego en Línea personas jurídicas nacionales o extranjeras con dos años de experiencia en el rubro y tener un patrimonio neto demostrable de USD 25.000.000.

Los titulares de los permisos, deberán pagar un canon anual USD 100.000 y constituir una garantía de cumplimiento de USD 2.000.000. Estos permisos que obtengan no serán transferibles.

\section{CAPÍTULO SEGUNDO ¿Cómo está regulada la explotación de los casinos en los distintos paí- ses de la región?}

\section{MARCO REGULATORIO DE CASINOS DE JUEGO EN CHILE ${ }^{17}$}

En Chile, la industria de los casinos comenzó hace más de 80 años con la autorización para establecer un casino en la ciudad de Viña del Mar. A partir de ese momento, y hasta principios de los años '90, se autorizaron seis (6) licencias adicionales con el formato de concesiones municipales, en diferentes ciudades turísticas, cronológicamente: Arica, Puerto Varas, Coquimbo, Iquique, Pucón y Puerto Natales, conformando así una industria de siete casinos a lo largo de Chile.

Posteriormente, en el año 2005 se promulga la Ley $\mathrm{N}^{\mathrm{o}} 19.995$ que establece las bases generales para la Autorización, Funcionamiento y Fiscalización de Casinos de Juego. Así fue que a través de su artículo 3ero, definió como juegos de azar sólo aquellos contenidos en el Catálogo de Juegos de la Superintendencia de Casinos de Juego, como: máquinas de azar, ruleta, juegos de cartas (donde destacan los derivados del póker, blackjack y punto y banca) juegos de dados, como el tradicional craps y, por último, el bingo.

Mediante esta ley, el Estado de Chile impulsó la industria de casinos de juego, ampliándose en 18 nuevas licencias, cada una de ellas con una duración de 15 años, y limitando el número de casinos de juego que pueden funcionar a un máximo de 24 a nivel nacional.

17 https://www.enjoy.cl/newsletter/2019/memoria/pdf/cap3.pdf 
En términos de distribución geográfica, la Ley N 19.995 establece que cada región puede contar con hasta tres casinos, con una restricción de localización geográfica que indica que deben estar a más de $70 \mathrm{~km}$ viales unos de otros, independientemente de la región en la que se localicen. La única excepción es en la ciudad de Arica, comuna a la cual no se le aplican dichos criterios.

La ley N 19.995 establece también la creación de la Superintendencia de Casinos de Juego (SCJ), con el propósito de regular la industria de los casinos generada a partir de la nueva normativa, y con la misión de promover un desarrollo eficiente, responsable y transparente bajo altos estándares de cumplimiento de la normativa. Dicha Superintendencia regula y fiscaliza las operaciones de casinos, con jurisdicción limitada a los centros de juego creados a partir de la Ley Nº 19.995.

Los casinos que operan bajo régimen de concesión municipal, están bajo los poderes regulatorios y sancionadores de sus respectivos municipios. Lo anterior, hasta que se autorice el inicio de operación de las nuevas licencias otorgadas por la Superintendencia de Casinos, tras el proceso de licitación que culminó en 2018. Como ente responsable de otorgar, renovar y revocar los permisos de operación de casinos de juego en el país, a la SCJ le corresponde también fiscalizar y accionar ante los tribunales de justicia respecto de la explotación o práctica de juegos de azar desarrollados al margen de la ley por personas o entidades no autorizadas.

En Chile, de conformidad a la Ley No 19.995 y sus Reglamentos, los principales derechos y deberes de las sociedades operadoras son los siguientes:

- Desarrollar los juegos incorporados oficialmente en el catálogo de juegos.

- Utilizar las máquinas e implementos de juego de azar que se encuentren previamente homologados en el registro que lleva la Superintendencia de Casinos de Juego.

- Funcionar solo en el establecimiento individualizado en el permiso de operación.

- Mantener de manera permanente una reserva de liquidez suficiente para responder a las apuestas que se realicen diariamente en el establecimiento.

- Funcionar todos los días del año, salvo aquellos días de excepción establecidos por ley. En todo caso, ningún casino de juego, cualquiera sea el día o época del año, podrá funcionar menos de seis horas al día.

- Contar con ciertos cargos mínimos dentro de su personal de juego, el cual deberá estar registrado en la nómina que llevará la Superintendencia de Casinos de Juego.

- Ofrecer y explotar aquellos servicios anexos contemplados en el respectivo permiso de operación.

Con fecha 11 de agosto de 2015 se publica la Ley $\mathrm{N}^{\mathrm{o}} 20.856$, que modifica la Ley $\mathrm{N}^{\mathrm{o}} 19.995$ y que, entre otros aspectos, prorroga el funcionamiento de los casinos municipales hasta el 31 de diciembre de 2017. Adicionalmente, a partir del 1 de enero de 2018, todos los casinos que hasta ese momento son municipales estarán sometidos a la misma regulación que el resto de la industria, entregando un 10\% de sus ingresos 
al gobierno regional y al menos un $10 \%$ a la municipalidad de su respectiva comuna. Cabe destacar, que la Ley $\mathrm{N}^{\circ} 20.856$ otorga el derecho a las comunas en las que hoy se encuentran los casinos municipales, a ser sede de casinos por 3 períodos consecutivos de 15 años cada uno.

\section{Juego Online}

La normativa reguladora de la industria de Casinos (esto es tanto la Ley como sus reglamentos), prohíben que los permisos de operación comprendan juegos de azar en línea.

Esto quiere decir que una Operadora no puede desarrollar juegos on line, pues ello está impedido por Ley, y sólo si hay una modificación legal podría ser autorizada administrativamente para ello.

Por otro lado, el Código Penal Chileno sanciona como delito "ofrecer" juegos de azar sin contar con autorización legal para ello.

Como consecuencia de lo anterior, si la Operadora "ofrece", "propone", "invita", publicita", etc. juegos de azar vía Internet, sin autorización legal, las personas naturales que se determinen como responsables de ello (gerentes, representantes) podrían ser sancionados penalmente.

\section{MARCO REGULATORIO DEL JUEGO EN ARGENTINA}

En lo que respecta a la regulación del juego, conforme lo establece la Constitución Nacional Argentina, hay que reparar respecto a la división de competencias entre la Nación y las Provincias. En ese sentido, y de acuerdo con art. $121^{18}$ de la Constitución Nacional, las provincias conservan todo el poder no delegado por éstas -a través de la Constitución- al Gobierno Federal, y el que expresamente se hayan reservado por pactos especiales al tiempo de su incorporación.

De modo que, en Argentina, la regulación de los juegos de azar es una facultad reservada a cada provincia, por lo tanto, cada jurisdicción establece sus propias reglas y regulaciones que se aplican a todos los titulares de licencias.

Así es o que la industria de juegos de azar en Argentina, regulada a nivel provincial, se compone de loterías, salas de juego y carreras de caballos.

Por ejemplo, en la provincia de Mendoza, el otorgamiento de las concesiones para la explotación de juegos de azar se encuentra regulado por la Ley provincial $\mathrm{N}^{\circ} 5.775 \mathrm{del}$ año 1991, y su Decreto reglamentario No 2235/1992, y es el Instituto Provincial de Juegos y Casinos (IPJyC) el ente responsable de regular las actividades de juego. De modo que, en la actualidad, en Mendoza conviven dos modelos de explotación de casinos. El primero se refiere a aquellos cuya explotación está a cargo del Instituto Provincial de Juegos y Casinos, quien entrega a un tercero la provisión de máquinas y servicios, mediante licitación pública. Así, bajo este sistema funcionan cinco salas de juego: el Casino de

18 Artículo $121 \mathrm{CN}$ : "Las provincias conservan todo el poder no delegado por esta Constitución al Gobierno federal, y el que expresamente se hayan reservado por pactos especiales al tiempo de su incorporación." 
Mendoza sede central y 4 anexos. El segundo régimen contemplado en la Ley provincial $\mathrm{N}^{\mathrm{o}} 5.775$ es de explotación privada, que permite la instalación y funcionamiento de salas de juegos en hoteles de categoría "cinco estrellas Internacional", que resulten de nuevos emprendimientos y se encuentren ubicados dentro del tejido urbano de las ciudades de Mendoza, Godoy Cruz, Las Heras y Guaymallén.

De acuerdo con esta ley provincial de Mendoza, sólo puede destinarse a las salas de juego el $4 \%$ de la superficie cubierta total del establecimiento. Bajo este sistema funcionan de manera permanente siete casinos. Las licencias concedidas a los privados para operar, se extienden de manera vitalicia, con excepción de un casino en particular, que tiene licencia con vigencia hasta el año 2033. En materia de impuestos, desde 2017 la ley de impuesto a las ganancias y la alícuota de ese impuesto (que es nacional) pasaron de $35 \%$ a 41,5\%; y se creó un impuesto específico a las apuestas de máquinas de azar.

En la provincia de Mendoza, el juego clandestino es considerado un delito grave e imputable con una condena que va de 3 a 6 años de prisión. El delito incorporado a la legislación penal se convierte en útil herramienta en la lucha contra el juego clandestino, respetando que el monopolio para la determinación del alcance y ámbito del juego es de la Provincia.

\section{Juego online}

En lo referente al juego online en Argentina, sigue la misma línea que el juego presencial. De modo que es una facultad reservada a cada provincia, por lo tanto, cada jurisdicción establece sus propias reglas y regulaciones que se aplican.

En línea de lo anterior, tal como mencionado bajo el capítulo de online más arriba, en la ciudad de Buenos Aires, tal como fuera analizado en con fecha 20 de febrero de 2020, el gobierno de la ciudad de Buenos Aires, aprueba la convocatoria para el otorgamiento de permisos de agencias de juego en línea siempre y cuando cumplan determinados requisitos.

En cuanto a antecedentes jurisprudenciales es importante mencionar el antecedente de Bwin Argentina S.A., que se tramitó ante el Tribunal Superior de Justicia de la Ciudad Autónoma de Buenos Aires ${ }^{19}$. La empresa Bwin Argentina S.A. empresa constituida en Argentina, consiguió la autorización para operar en el segmento de juegos de apuesta solamente en la provincia de Misiones. Sin embargo, por laS características de la plataforma utilizada por Bwin para proveer el servicio de apuestas (la página web: www.Bwin.com.ar), cualquier persona dentro del territorio argentino podía acceder a dicho sitio y realizar apuestas. Con posterioridad y previo el inicio de un procedimiento contravencional, pudo determinarse que usuarios situados en la Ciudad Autónoma de Buenos Aires habían accedido a la plataforma y habían realizado apuestas online a través de Bwin. A raíz de esto, se determinó que la firma había infringido el Código de Contravenciones de la Ciudad Autónoma de Buenos Aires, por cuanto apostadores de dicha localidad tenían acceso a la página web y por ende podían utilizar el producto. El problema residía en que Bwin no poseía autorización para funcionar en la Ciudad

19 "W, Armando Andrés y Bwin Argentina SA s/queja por recurso de inconstitucionalidad denegado", Tribunal Superior de Justicia de la Ciudad Autónoma de Buenos Aires, 08/04/2009. 
de Buenos Aires, y por lo tanto el hecho de que un apostador situado en dicha ciudad realizara una apuesta, constituía una infracción.

Ahora bien, es preciso destacar que en el caso contra Bwin, se trataba de una sociedad argentina y que funcionaba con el dominio ".com.ar", por ello fue posible realizar la clausura preventiva de la página web, restringiendo su ámbito de aplicación con respecto a los límites de la Ciudad de Buenos Aires.

\section{MARCO REGULATORIO EN BRASIL}

En Brasil, a diferencia de lo que ocurre en Uruguay, Argentina y Chile, el juego está prohibido.

Esto surge del artículo 50 de la Ley de Contravenciones penales el cual establece que:

Art. 50. Estabelecer ou explorar jogo de azar em lugar público ou acessivel ao público, mediante o pagamento de entrada ou sem ele: (Vide Decreto-Lei $n^{\circ}$ 4.866, de 23.10.1942) (Vide Decreto-Lei 9.215, de 30.4.1946)

Pena - prisão simples, de três meses a um ano, e multa, de dois a quinze contos de réis, estendendo-se os efeitos da condenação à perda dos moveis e objetos de decoração do local.

$\S 1^{\circ}$ A pena é aumentada de um terço, se existe entre os empregados ou participa do jogo pessoa menor de dezoito anos.

$\S 2^{\circ}$ Incorren a pena de multa, de duzentos mil réis a dois contos de réis, quem é encontrado a participar do jogo, como ponteiro ou apostador.

$\S 2^{\circ}$ Incorrena pena de multa, de $R \$ 2.000,00$ (dois mil reais) a $R \$ 200.000,00$ (duzentos mil reais), quem é encontrado a participar do jogo, ainda que pela internet oupor qualqueroutromeio de comunicação, como ponteiroou apostador. (Redação dada pela Lei $n^{\circ} 13.155$, de 2015)

$\S 3^{\circ}$ Consideram-se, jogos de azar:

a) o jogoem que o ganho e a perda dependem exclusiva ou principalmente da sorte;

b) as apostas sobre corrida de cavalos fora de hipódromo ou de local onde sejam autorizadas;

c) as apostas sobre qualquer outra competição esportiva.

$\S 4^{\circ}$ Equiparam-se, para os efeitos penais, a lugar acessivel ao público:

a) a casa particular em que se realizam jogos de azar, quando deles habitualmente participam pessoas que não sejam da família de quem a ocupa; 
b) o hotel ou casa de habitaçãocoletiva, a cujoshóspedes e moradores se proporciona jogo de azar;

c) a sede oude pendência de sociedade ou associação, em que se realiza jogo de azar;

d) o estabelecimento destinado à exploração de jogo de azar, ainda que se dissimule esse destino.

De modo que, a diferencia de Uruguay, Argentina y Chile, donde los juegos de azar es una actividad reservada al Estado. En Brasil se encuentra prohibido.

Esto ha sido así históricamente. Adicionalmente los juegos de azar, a través de cualquier plataforma, estaban prohibidos y constituyen formalmente un delito. (Incluida la plataforma online)

La prohibición anterior abarcaba "establecer" juegos de azar, lo que significa proporcionar el acceso a tales juegos; y "explotar" dichos juegos de azar, lo que significaba obtener beneficios de parte de terceros.

Las sanciones iban desde prisión de 3 meses a 1 año, hasta multa. La multa también es imponible a los jugadores brasileños.

Sin perjuicio de lo anterior, el pasado 12 de diciembre de 2018, se promulgó la ley 13756 a través de la cual se aprueba las apuestas deportivas en Brasil. Esto puede ser interpretado como un primer paso en Brasil hacia la legalización del juego.

A través de esta ley, se permite la realización de apuestas relativas a eventos reales vinculados al deporte, donde se encuentra definido el momento de efectivización de la apuesta, cuando el apostador puede ganar en caso de acierto del pronóstico. Estas apuestas son denominadas apuestas de cuota fija.

Adicionalmente se estableció, esta modalidad de apuesta puede ser comercializada a través de cualquier canal de distribución comercial físico, como también en medios virtuales como las apuestas online.

El Ministerio de Hacienda (Minsterio da Fazenda), es el responsable de otorgar las autorizaciones y concesiones de loterías y apuestas de cuota fija, y será la encargada de reglamentar la actividad en un plazo de dos años, prorrogables por igual período desde la publicación de la Ley.

A la fecha únicamente existen sitios de apuestas deportivas extranjeras en Brasil

Esta nueva ley también permite a su vez los patrocinios deportivos.

Por su parte, al día de hoy existen más de 10 proyectos de Ley tendientes a permitir regular el juego en Brasil viéndose estancados cada uno de ellos por diferentes motivos. 


\section{CAPÍTULO FINAL: CONCLUSIÓN ¿El sistema actual es el mejor para desarrollar la explotación de los casi- nos en Uruguay?}

Luego de analizado el sistema por el cual se ha explotado el casino por parte del Estado en el Uruguay desde el siglo XIX. Un sistema prohibitivo pero que fue vanguardista para su época permitiéndole desarrollar los juegos de azar de una manera segura y beneficiándose directamente por mayores ingresos e indirectamente a partir de una mayor oferta turística.

Por lo tanto, y a las pruebas de más de un siglo de explotación de los juegos de azar ya sea por el Estado como a través de privados autorizados por este, me llevan a afirmar que el sistema adoptado por Uruguay ha sido un sistema eficaz. Máxime en comparación con el desarrollo del juego en países vecinos.

Sin perjuicio de lo anterior, tal como fue señalado, entiendo que es momento de actualizar el marco normativo a los efectos de dar respuesta a los temas que han ido surgiendo en el correr de los años, y en especial a temas de actualidad tales como la proliferación de máquinas tragamonedas clandestinas y el juego on-line.

En línea de lo anterior, entiendo que se dejó pasar una muy buena oportunidad de aprobar un proyecto de ley integral que contemple buena parte de los principales temas del rubro. El anterior proyecto, aunque mejorable en varios aspectos, pretendía en primer lugar ratificar el monopolio del Estado sobre los juegos de azar y apuestas, enmarcando dentro de estos a los casinos, las actividades hípicas, loterías y quinielas y el juego online.

A su vez, buscaba a través del proyecto construir un marco integral distinguiendo las funciones de regulación y control, de aquellas de explotación directa por parte del Estado. Entiendo que esto es uno de los pilares fuertes de dicho proyecto, dado que en la actualidad muchas veces estos roles tienden a confundirse.

De esta forma, se procedería crear un órgano de contralor capaz de regular y fiscalizar todo lo relativo a las prohibiciones o autorización de explotación de juegos de azar, así como sancionar administrativa y penalmente a los infractores.

Entiendo que ese es el camino que se debiera seguir, teniendo un órgano responsable no solo de controlar y fiscalizar, sino autorizado en base a requisitos previamente acordados a aquellos que pretendan desempeñar el negocio de tragamonedas. Así se podría autorizar el juego en condiciones acordadas y controlar aquellos que lo hagan al margen del mismo. De esta forma se regularizaría por un lado y erradicaría el funcionamiento de organizaciones al margen de la legalidad, la evasión fiscal, la normativa de protección a menores y el lavado de activos.

Por último, este proyecto buscaba garantizar la transparencia de la explotación de los juegos de azar y sorteos eventualmente asociados a ellos. De forma así de proteger al consumidor, asegurando la ausencia de prácticas dolosas para el público apostador. 
Todo lo anterior redunda en un mejor servicio para los consumidores y mayores garantías para los explotadores de los juegos de azar.

De modo que a las claras queda expuesto la necesidad de unificar toda la normativa reinante en un único marco normativo integral. Entiendo que este marco normativo, debiera recoger los principales aspectos mencionados en el proyecto de ley anterior, regulando a su vez la naturaleza de las obligaciones que emanan del juego de azar autorizado aclarando expresamente que se tratan de obligaciones civiles.

Por último, manteniendo el carácter prohibitivo del mismo, debería ahondar en las posibilidades de ampliar su espectro a las nuevas realidades del rubro. Para tal fin debiera hacer inclusivo un capítulo serio de como regularizar el juego on-line dándole la posibilidad (al igual que como ocurre con los casinos) que puedan ser explotados por los privados en base a las mejores prácticas en el mundo.

\section{APÉNDICES}

\section{A. APÉNDICE NORMATIVO}

- Constitución de la República

- Ley 1595 de 16 de diciembre de 1882 que establece el sistema prohibitivo para desarrollar los juegos de azar en el Uruguay.

- Ley 5352 del 20 de noviembre 1915 facultó al Poder Ejecutivo a autorizar a la IMM la organización de juegos de azar y concesiones en zonas balnearias.

- Ley 10.709 de 1946 autoriza a la Intendencia Municipal de Montevideo (IMM) a desarrollar la actividad de casinos en hoteles propiedad de ésta.

- Ley 13.921 del 04 de diciembre de 1970 el cual faculta al Poder Ejecutivo para explotar directamente juegos de azar en hasta nueve Casinos instalados o a instalarse

- Código civil

- Leyes $\mathrm{N}^{\mathrm{o}} 14.178$ de 28 de marzo de 1974 y No 16.906 de 7 de enero de 1998 y decretos reglamentarios.

- Ley 17.250 del 17 de agosto del 2000. Ley de defensa del consumidor

- Ley 17.296 de 23 de febrero de 2001 relativo a determinadas facultades de la Dirección General de Casinos

- 17.555 de 19 de setiembre de 2002. Ley de reactivación económica

- Ley 17.823 (Código de la niñez y la adolescencia) del 14 de septiembre de 2004

- Ley 18.231 del 9 de enero de 2008 (sofitel)

- Ley 18.256 10 de marzo de 2008. Ley de medio ambiente libre de humo de tabaco

- Ley 18719 de 05 de enero de 2011 promueve la actividad hípica a nivel nacional y la supervisión del juego de apuestas mutuas en todas sus modalidades. 
- Ley 19535 de 03 de octubre de 2017. Ley de rendición de cuentas

- Ley 19574 (modificativa de la 17.835) del 10 de enero 2018. Ley integral contra el lavado de activos

- Decreto Ley 14189 del 30 de abril de 1974. Ley de rendición de cuentas ejercicios 1971 y 1972

- Decreto ley 14335 de 1975. Ley de turismo

- Ley 15.20619 de noviembre de 1981

- Texto Ordenado de Contabilidad y Administración Financiera (T.O.C.A.F.), aprobado por el Decreto No 150/012 de 11 de mayo de 2012

- Decreto N $500 / 991$ de 27 de setiembre de 1991.

- Decreto 588/1975 de 24 de julio de 1975.

- Decreto 366/017 de fecha 21 de diciembre de 2017

- Decreto 63/97 (complementado por el 488/08 y el 302/2009) del 04 de marzo de 1997

- Decreto 269/93 el 14 de junio de 1993

- Decreto 379/2018 del 12 de noviembre 2018

- Decreto 284/08 09 de junio de 2008

- Digesto Municipal No9 de la Intendencia Municipal de Montevideo

\section{NORMATIVA EXTRANJERA}

- Ley 19995 y 20.856 (Chile).

- Ley 5775 (Provincial de Mendoza, Argentina)

- Resolución de directorio del Gobierno de la Ciudad de Buenos Aires.

- Ley de contravenciones, Brasil.

- Acuerdo número 04 del 24 de mayo de 2016 (Colombia)

- Professional and Amateur Sports Protection Act (Estados Unidos)

\section{B. BIBLIOGRAFÍA PROPUESTA}

- Delpiazzo, Carlos E. Derecho Administrativo Especial V.2. $3^{\text {a }}$.ed. Montevideo: Amalio M. Fernández, 2017

- Durán Martínez, Augusto. Instalación de un casino en Portezuelo pp.183-186. En: Durán Martínez, Augusto. Casos de Derecho Administrativo.V.1. Montevideo: INGRANUSI, 1999, 202 p

- Durán Martínez, Augusto. Máquinas tragamonedas: régimen jurídico. En: Estudios de Derecho Administrativo No. 13 (2016), pp. 851-879. Comentario a la sentencia 381 del 30 de setiembre de 2014 del Tribunal de lo Conten 
- Durán Martínez, Augusto. Un caso de explotación de casinos en el llamado régimen mixto pp.81-90. En: Durán Martínez, Augusto. Casos de derecho administrativo. V.6. Montevideo: A. Durán, 2010, 410p

- Gamarra, Jorge. Tratado de Derecho Civil uruguayo, T.1.3 $3^{\text {a }}$ ed. Montevideo: Martín Bianchi Altuna, 1981

- López Fernández, Sestella; Alvarez Rego, Marcos. Banca colectiva de quinielas: un caso de responsabilidad. En: Revista Uruguaya de Derecho Constitucional y Politico, Tomo 7, Número 42 (abr.-mayo 1991), p.518-525

- Peirano Facio, Jorge. Curso de contratos T.5. Montevideo: Centro de Estudiantes de Derecho, 1963

- Silva Forné, Diego. Juegos de azar, tutela penal de la propiedad y delito de juego de la mosqueta. En: Revista de Derecho Penal, Número 12 (jul.2001), pp.87-102

- Venturini Camejo, Beatriz; Feuer, Sofía. Contratos aleatorios: juego y apuesta pp.499-509. En: Venturini Camejo, Beatriz, coord. Manual de contratos T.2. Montevideo: Universidad de Montevideo. Facultad de Derecho, 2014

- Ludopatia, un estudio comparativo entre realizado en Italia y España. Humanismo y trabajo social, Vol 7, 2008pp 155-196 Universidad de Leon, España. https:/ / www.redalyc.org/pdf/678/67811462007.pdf

- Online gaming sector. Diversification and scale for online success. Julio 2019. https://www.edisongroup.com/wp-content/uploads/2019/07/GamingSectorReport2019.pdf

- https://www.igamingbusiness.com/analysis/wiggin-european-regulation-roundup-may-2020 